\title{
Probabilistic Seismic Evaluation and Experimental Tests of Multi-Direction Damping System on a Super-Long Column-Pylon Cable-Stayed Bridge
}

Jian Zhong ( $\square$ jzhong@hfut.edu.cn )

Hefei University of Technology https://orcid.org/0000-0002-5998-250X

Liang Chen

Hefei University of Technology

Ruihan Su

Hefei University of Technology

$\mathrm{Ke} \mathrm{Hu}$

Anhui Transport Consulting \& Design Institute Co.,Ltd

\section{Research Article}

Keywords: Multi-direction damping system, super-long cable-stayed bridge, experimental test, seismic fragility analysis, transversal seismic control

Posted Date: March 7th, 2022

DOI: https://doi.org/10.21203/rs.3.rs-1402280/v1

License: (9) This work is licensed under a Creative Commons Attribution 4.0 International License. Read Full License 


\title{
Probabilistic Seismic Evaluation and Experimental Tests of Multi-Direction Damping System on a Super-Long Column-Pylon Cable-Stayed Bridge
}

\author{
Liang Chen ${ }^{1}$, Ruihan $\mathrm{Su}^{1}, \mathrm{Ke} \mathrm{Hu}^{2}$, Jian Zhong ${ }^{1, *}$ \\ ${ }^{1}$ Department of Civil Engineering, Hefei University of Technology, Hefei, Anhui, 230009, \\ People's Republic of China \\ ${ }^{2}$ Anhui Transport Consulting \& Design Institute Co.,Ltd, Hefei, Anhui, 231299, People’s \\ Republic of China \\ *Correspondence to: Jian Zhong, Hefei, 230009, PR China. E-mail: jzhong@hfut.edu.cn
}

\begin{abstract}
In view of the insufficiency of bidirectional seismic control of long span cable-stayed bridges as well as the limitations of existing schemes, a multi-direction damping system (MDDS) was proposed and investigated in this manuscript, which can provide seismic resistance bidirectionally. The new damping system owned a unique middle connecting structure, which overcomes the disadvantages that axial instability caused of excessive long rod and the demand of large installing space of traditional dampers. Both the performance stability and constitutive relationship of MDDS were verified by engineering tests, and the equivalent design method was then proposed and proved to be applicable. A detailed finite element numerical model of a super-long (main span over $800 \mathrm{~m}$ ) column-pylon cable-stayed bridge which equipped with MDDS in practice was established, the fragility curves of critical components were obtained by non-linear time history analysis, which exhibited the high efficiency of MDDS seismic performance in both transversal and longitudinal directions. Through extracting the median fragility value of 35 sections of the pylon under four damping cases i.e. setting dampers transversely (TDS), longitudinally (LDS), bidirectionally (BDS) and MDDS, it can be concluded that MDDS performed far better on seismic resistance than LDS and TDS, and made the similar contribution with BDS. On account of half number of damper setting and the reduction in installing space demand, MDDS becomes the optimal choice in practical application for its economical efficiency and superiority. Furthermore, the optimal horizontal installing angle of MDDS was derived through six angle cases which was based on the system-level fragility curves comparison.
\end{abstract}

\section{Keywords}

Multi-direction damping system, super-long cable-stayed bridge, experimental test, seismic 
fragility analysis, transversal seismic control

\section{Introduction}

Large-span cable-stayed bridges are increasingly used in practical engineering applications for their excellent span capacity, stability and magnificent appearance [1]. With the amount of cable-stayed bridges increasing all around the world, their status in traffic engineering is more vital. Therefore, the seismic research of cable-stayed bridges has become a decisive investigating topic of many scholars and engineers.

For the low structural damping and long natural periods of cable-stayed bridges, their structures are high flexible and vulnerable under earthquake actions [2]. The post-earthquake field observation indicates that one of the outstanding damage sources of long-span cable-stayed bridge is that the large relative displacement of the components and adjacent spans [3,4], especially at the girder-pylon junction [5], which makes the deformation capacity of the expansion joint and the reserved clearance cannot meet the seismic needs [6]. Therefore, it becomes particularly critical for the selection of seismic constraint design on cable-stayed bridges. A fully rigid connection has been proven would effectively control the displacement of the girder transversely, but would lead to excessive bending moments and shear forces of the pylons in the longitudinal direction [7]. In order to restrict the longitudinal displacement of the girder and weaken responses transferred to the pylon, the elastic displacement limiting device with high damping is often used at the girder-pylon location [8]. A numerous schemes of longitudinal constraint design $[9,10,11]$ have been proposed and developed.

Relatively, the transversal seismic system of cable-stayed bridge is more complex and diverse. According to many scholars, supplementary damping system (SDS) [12] has become the mainstream design scheme of transversal seismic fortification system for bridge structures. SDS is an auxiliary equipment system set in specific parts of the bridge. The advantages [13] of that devices are simple design, convenient repair, low cost and even guarantee traffic obstruction prevention while maintenance and repairing.

Aiming at an asymmetric single pylon cable-stayed bridge, He et al. [14] put forward and designed a cable sliding friction ball bearing support system, and studied its transversal seismic performance under the action of strong earthquake. The result showed its efficiency in reducing the internal force of the structure and the transversal displacement of the members. Shen et al. [15] discussed three design schemes of viscous fluid damper, friction pendulum sliding bearings and transversal yielding metallic dampers on a large-span cable-stayed bridge and the conclusion showed that transversal yielding metallic damper does not interact with the longitudinal 
displacement of the girder while the other two cases were opposite. Guan et al. [16] proposed a damper device scheme with low horizontal maintenance requirements of cable-stayed bridges, and proved its devotion in longitudinal and transversal seismic control. Camara [13] et al. designed a metal damper consisting of triangular plates connecting cross bridges to the girder plates and bearings, but proved that the damping device was no longer sensitive for bridges whose spans more than $600 \mathrm{~m}$. Niu [17] et al. developed a new type of variable stiffness oil damper, whose parameters are set to be low stiffness and high damping, which can be installed transversely between the girder-pylon and the girder-pier connecting position. Because of the low stiffness of wind resistance and isolation, this oil damper has better performance in controlling the transversal displacement of the girder.

However, the seismic design methods above are considered separately in one direction without taking the influence of the whole horizontal directions into account. In general, the transversal restraint system needs to be designed on the premise of meeting the longitudinal restraint system. If there is no transversal restraint, the girder displacement may exceed the transversal reserved clearance of the pylon and girder, resulting in the collision between them [18]. Therefore, most long-span cable-stayed bridges choose to install resistant bearings in the transversal directions as a conventional restraint pattern to withstand the relative displacement between the pylon and girder, as shown in Fig 1(a). But the stiffness of the structure is increased due to the consolidation system, and redundant structural responses will be generated under a large earthquake. In view of this problem, scholars [19,20,21,22] proposed various seismic control schemes on super-long cable-stayed bridges. Infanti et al. [23] innovated a seismic scheme on the Rion-Antirion Bridge in Greece with both transversal and longitudinal dampers, which are shown in Fig 1(b). However, both the longitudinal and transversal installation are limited by the reserved gap between the pylon and girder, which leads to great limitations on seismic design of different cable-stayed bridges.

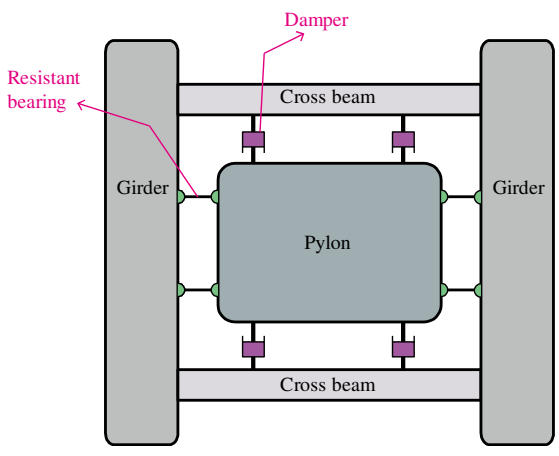

(a)

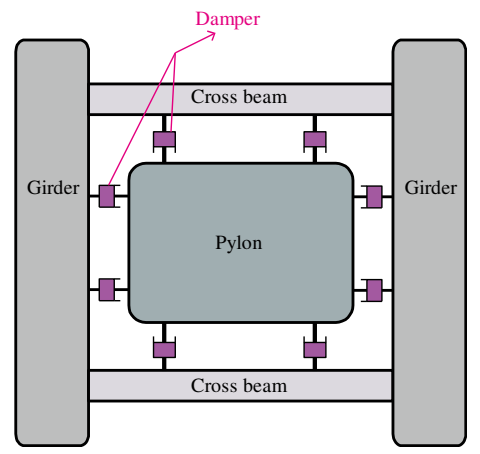

(b)

Fig 1. Conventional damping system: (a) dampers arranged longitudinally only, (b) dampers arranged bidirectionally 


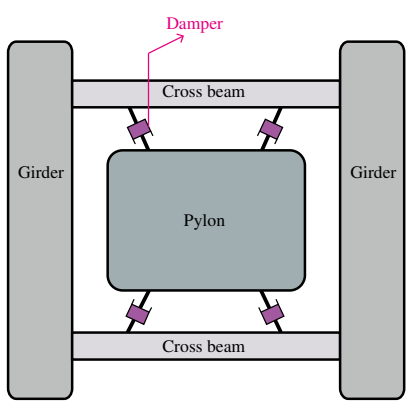

(a)

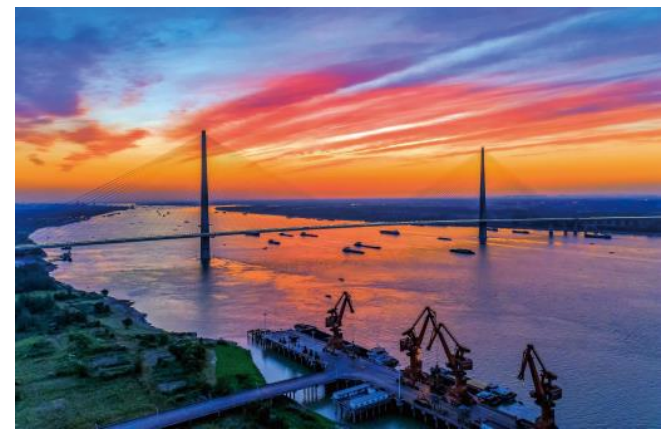

(c)

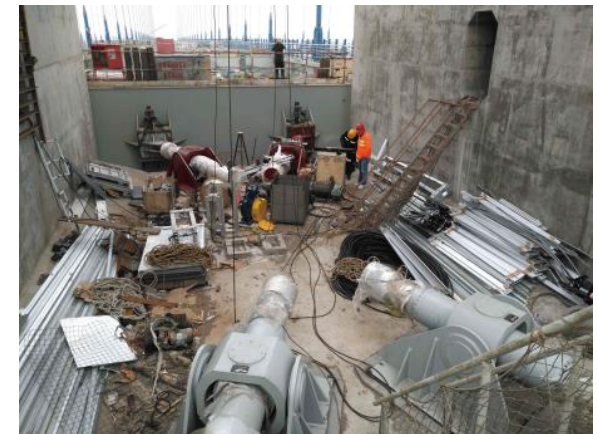

(b)

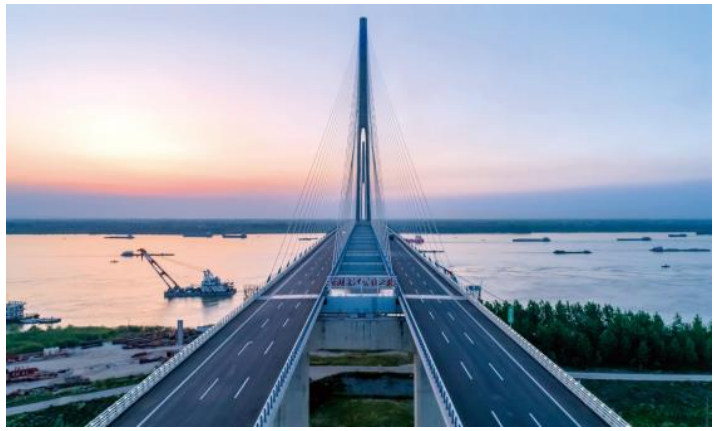

(d)

Fig 2. MDDS: A new multi-direction damping system : (a) (b) MDDS arrangement and installation site, (c) (d) practical pictures of the applied bridge which was equipped MDDS

In view of the insufficient consideration of existing seismic design of cable-stayed bridges, a multi-direction damping system (MDDS) is proposed and investigated in this manuscript, as shown in Fig 2(a) and (b), which can simultaneously reduce the transversal and longitudinal seismic responses of bridge structures under the condition of specific structure design and limited number of dampers arrangement. As an authorized invention patent, MDDS has been applied to a super-long cable-stayed bridge with the main span over $800 \mathrm{~m}$ in China which is shown in Fig 2(c),(d). In this investigation, by conducting experimental performance tests and numerical simulation, the performance of the new damping system and its equivalent design method were verified. And the seismic fragility analysis $[24,25,26,27]$ was then carried out based on non-linear time history analysis of the cable-stayed bridge which equipped with the MDDS, the results further confirmed the advantages of the new damping system in the practical engineering application.

\section{Multi-Direction Damping System (MDDS)}

\subsection{Structure features}

At present, the general connecting pattern of viscous dampers on long-span bridges are shown in Fig 3(a), which has the following shortcomings: 1) One end is fixed on the girder with 
the other end fixed on the bridge pylon (or pier) which lead to the large demand of installation space for the dampers; 2) As the damper is provided axial load, the long installing length makes the damper have the possibility of axial instability; 3) The damper setting direction is unique but various loads come from different directions to the structure, so that the general installation cannot cope with the seismic actions or other loads comprehensively.

Therefore, as shown in Fig 3(b), a new multi-direction damping system (MDDS) is designed in response to the existing deficiency of present seismic design on long-span cable-stayed bridges, and which has been applied in the reality. Firstly, a universal hinge support is set not only to connect the dampers but also to provide the middle support for the system. Its horizontal and vertical designed angle makes the system has self-adapting ability in seismic actions. Secondly, benefit by the middle support, the system reduces the demand of dampers installing space. Meanwhile, the possibility of axial instability due to large slenderness ratio is decreased because the MDDS has relative half stroke comparing with conventional damper. Thirdly, the oblique angle setting of MDDS can reduce bridge responses both in transversal and longitudinal direction simultaneously without increasing the number of dampers installation.

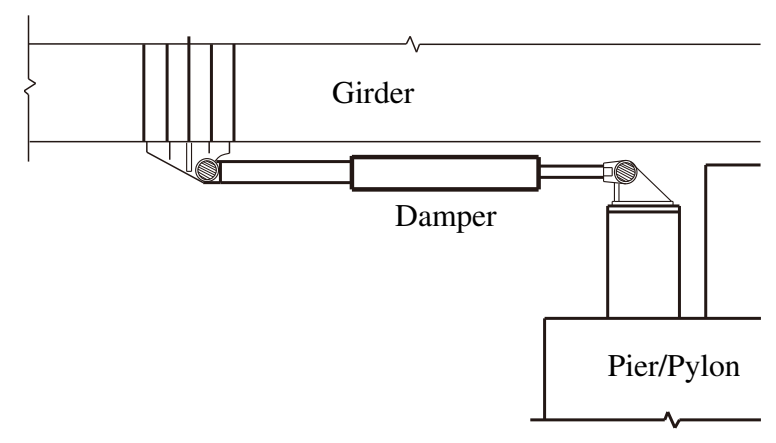

(a)

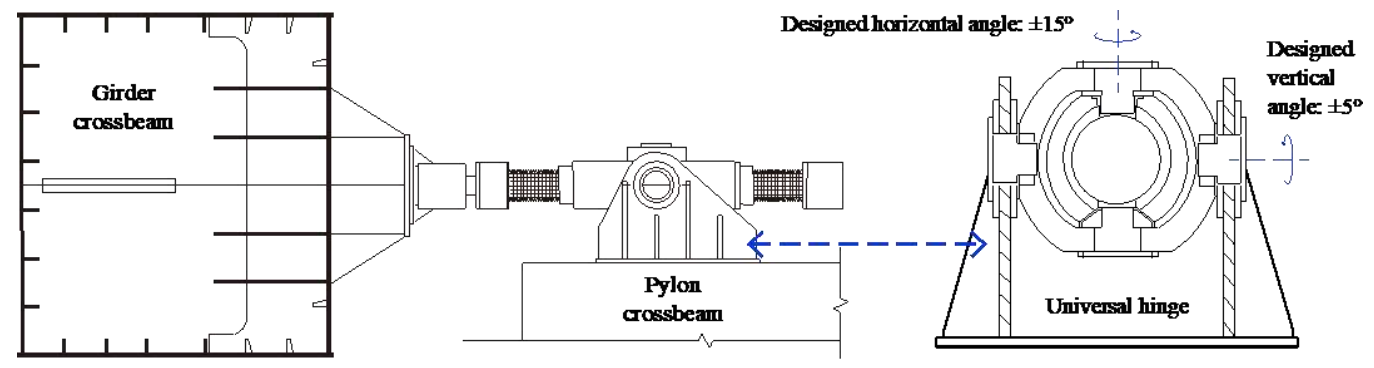

(b)

Fig 3. Damper installation schemes: (a) conventional installation; (b) MDDS installation and detailed diagram of its universal hinge support.

\subsection{Equivalent design method}

The MDDS is installed at the position that between the bridge pylon and the girder 
crossbeam. An MDDS contains four diagonally placed viscous dampers, each of which is equipped with a universal hinge support.The damper is at an angle of $25^{\circ}$ to the longitude direction, and the layout of MDDS is shown in Fig 4.

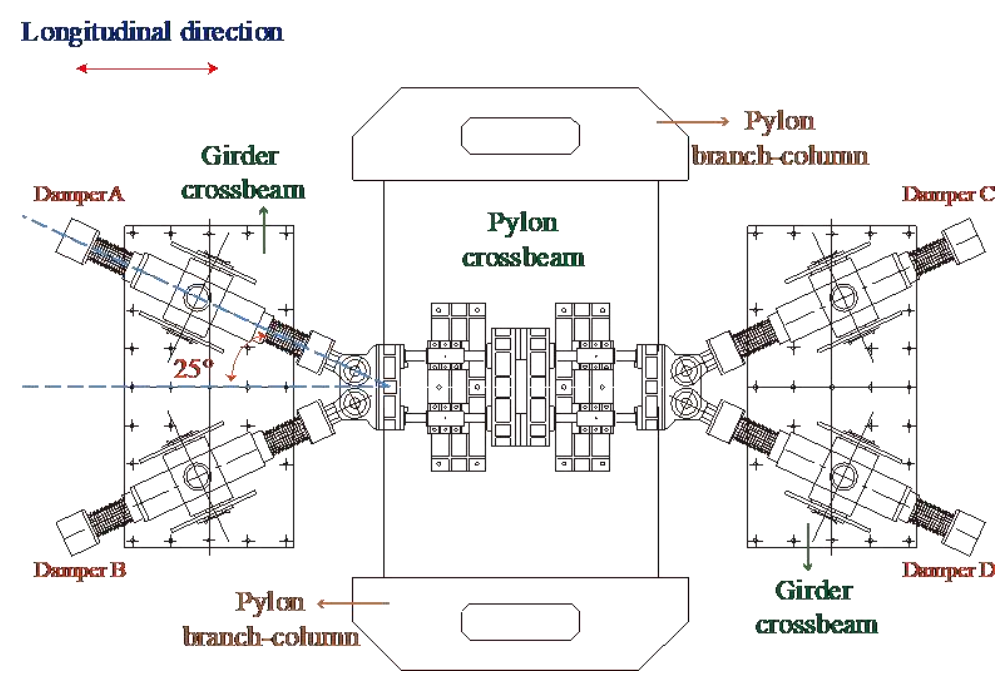

Fig 4. The layout of MDDS

Generally, the force-velocity relationship of the viscous damper is expressed by the following $\mathbf{E q ( 1 ) :}$

$$
f_{D}=C_{\alpha} \operatorname{sgn}(\stackrel{g}{u})\left|\frac{g}{u}\right|^{\alpha}
$$

In the above relationship equation, $f_{D}$ is the damping force, $C_{\alpha}$ is the damping coefficient which ought to be derived by experiments, $\dot{u}$ represents the relative velocity, $\alpha$ is the exponent which is used to simulate the viscous damper non-linear behaviour and $\operatorname{sgn}()$ is the sign function [28]. For the sake of brevity, the $\mathbf{E q ( 1 )}$ can be simplified by substituting $C_{\alpha}$ into $C$ and $\operatorname{sgn}(\dot{u})|\dot{u}|$ into $V$ [11], and the simplified formula is shown in the $\mathbf{E q ( 2 ) . ~}$

$$
F=C V^{\alpha}
$$

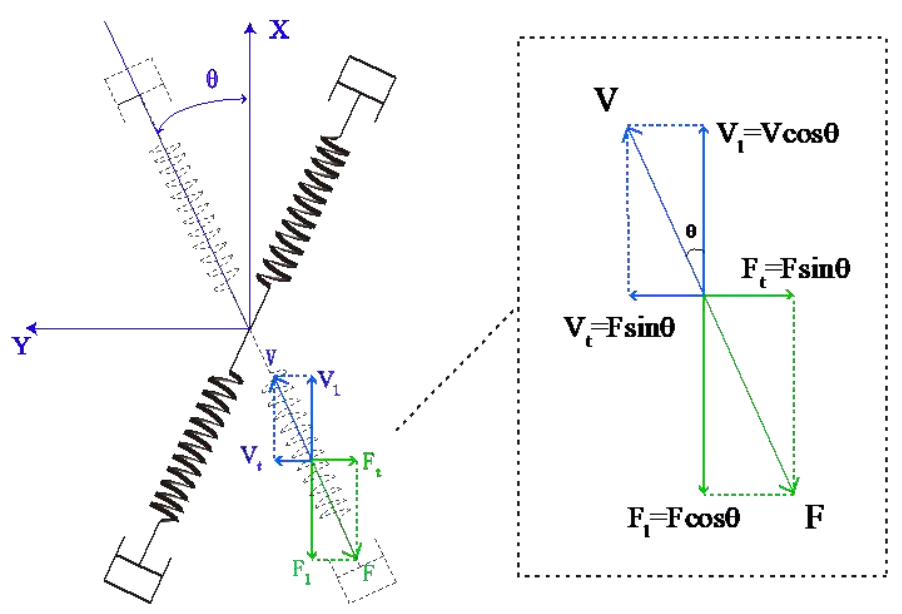


Fig 5. The mechanics relation of MDDS

As MDDS is provided axial velocity $V$ by wind load or seismic forces, according to force decomposition and geometric relationship conversion that are shown in Fig 5. The relationships among transversal and longitudinal relative velocities $V_{t}$ and $V_{l}$, the transversal and longitudinal component forces $F_{t}$ and $F_{l}$ of damping force $F$, the component damping coefficient $C_{t}$ and $C_{l}$ are respectively exhibited. Therefore, a general equivalent design method of MDDS is put forward.

Through the transformation of damping force $F$ by sin function, the transversal component force of $F$ i.e. $F_{t}$ can be derived:

$$
F_{t}=F \sin \theta
$$

Where, $F$ can be substituted by Eq (2) from which axial velocity $V$ can be further transformed into transversal component $V_{t}$, as shown in $\mathbf{E q}$ (4).

$$
F \sin \theta=C V^{\alpha} \sin \theta=C\left(\frac{V_{t}}{\sin \theta}\right)^{\alpha}=C V_{t}^{\alpha}(\sin \theta)^{1-\alpha}
$$

Hence, by observing the Eq (4), the component damping coefficient $C_{t}$ can also be expressed through the transformed $C$ :

$$
C_{t}=C(\sin \theta)^{1-\alpha}
$$

In conclusion, $F_{t}$ can be finally expressed by following $\mathbf{E q}(\mathbf{6})$ for $C_{t}$ and $V_{t}$ :

$$
F_{t}=C_{t} V_{t}^{\alpha}
$$

Similarly, the longitudinal damping component force $F_{l}$ and the the longitudinal component damping coefficient $C_{l}$ can be concluded below in Eq (7),(8):

$$
\begin{gathered}
F_{l}=C_{l} V_{l}^{\alpha} \\
C_{l}=C(\cos \theta)^{1-\alpha}
\end{gathered}
$$

Since MDDS has been applied to a super-long span cable-stayed bridge in practice, its initial design parameters in this study are set as settings of the practical bridge. The damping coefficient $C$ and damping exponent $\alpha$ are given as $3000 \mathrm{kN} / \mathrm{mm} \cdot \mathrm{s}^{-1}$ and 0.25 , respectively.

Aiming at the verification of the equivalent design method, a static analysis model of viscous damper was established. The model simulates the oblique angle of MDDS, carries on the load 
through the axial reciprocating load, extracts the axial local force and node displacement under the local coordinate system to reflects its hysteretic curve. In addition, two models set at $0^{\circ}$ (longitude) and $90^{\circ}$ (transverse) respectively were established to simulate the longitudinal(y) and transversal(x) components of MDDS. Parameter settings were based on Eq (6) and Eq (7) proposed above. See Fig 6 for schematic diagrams of the three models.

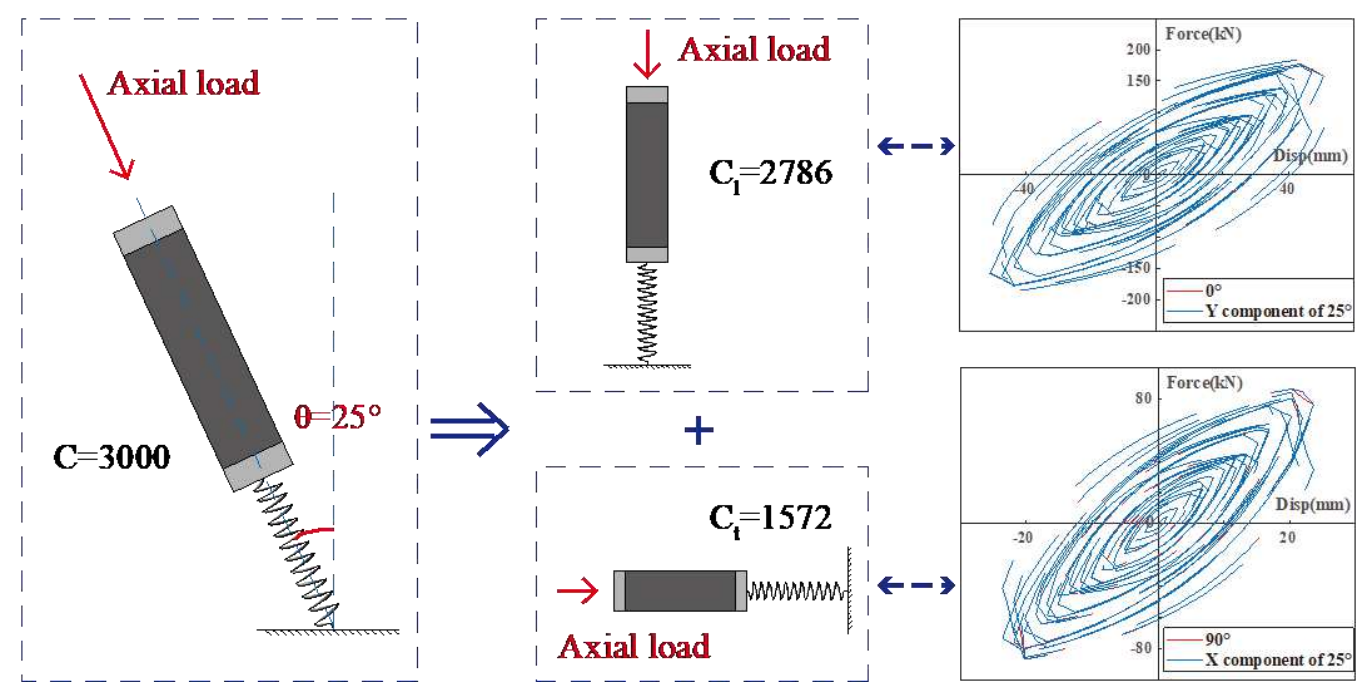

Fig 6. Verification of equivalent design method

By comparing the longitudinal and transversal components of the oblique model with the axial data of the other two models, it was found that the component hysteretic curves of the oblique model were consistent with the curves representing their respective simulated conditions. Thus, the verification confirms the correctness of the equivalent design method, which can be applied to the following case analysis.

\subsection{Experimental tests}

A scale model (1:2) of the universal hinge support was manufactured to testify its working performance. MTS electronic servo system was used to load on the model, which was shown in Fig 7(a). The model was designed according to the similitude theory [29], for whose parameters settings can be made to form similar constants with those of the structure prototype. The design load of a viscous damper in MDDS was $2200 \mathrm{kN}$, which can predict the required load of the scale model was $550 \mathrm{kN}$ for the stress similitude constant was 0.25 . The test model adopted the same material as the practical structure, and the test site was shown in Fig 7(b). And the measuring points of support A and B were selected as shown in the Fig 7(c) to (d), which also showed the strain rosette of each surface respectively. According to the loading test, the maximum principle stress of support $\mathrm{A}$ and support $\mathrm{B}$ are $\sigma_{\operatorname{maxA}}=74.8 \mathrm{MPa}$ and $\sigma_{\operatorname{maxB}}=163.1 \mathrm{MPa}$, so as the connecting component, universal hinge support was able to meet the structural strength 
requirements.

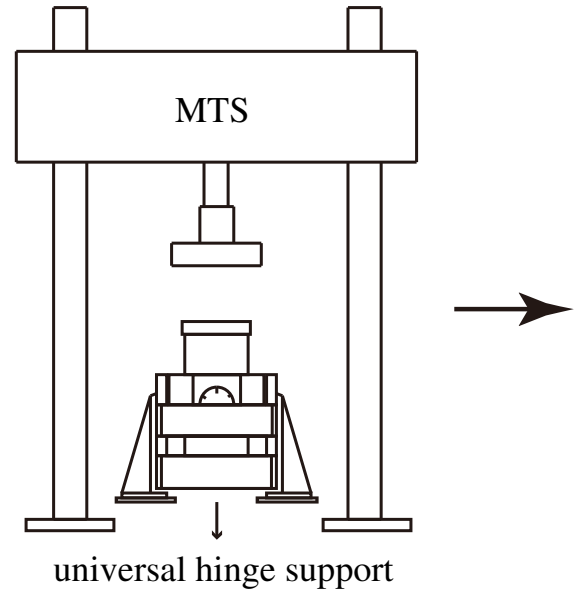

(a)

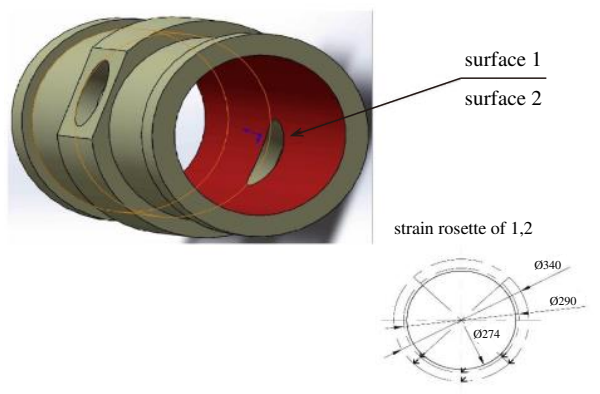

(c)

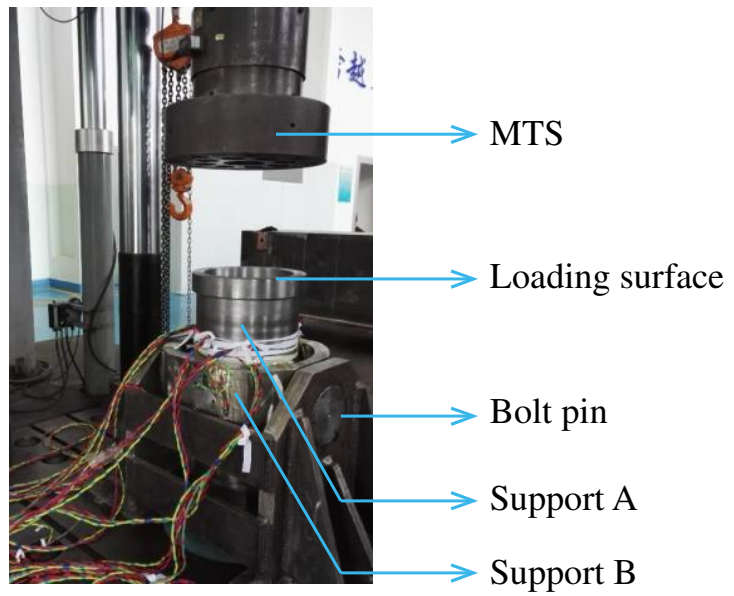

(b)

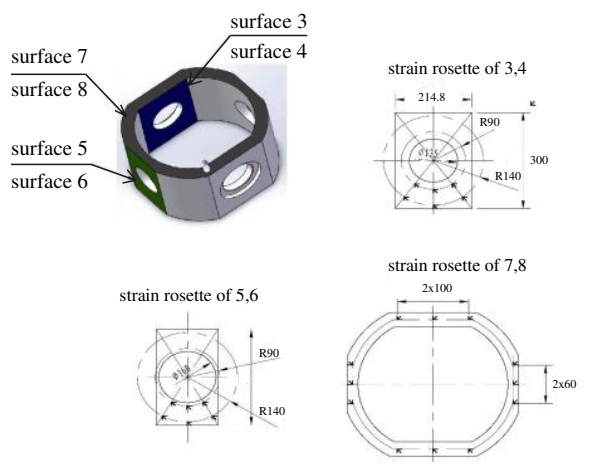

(d)

Fig 7. Loading test of universal hinge support: (a) loading diagram, (b) test of a scale model(1:2), (c) (d) measuring points arrangement and respective strain rosette

Viscous dampers performance tests were followed. A viscous damper was tested under five different velocity loading cases. The design maximum speed of the damper was $V_{\max }=289 \mathrm{~mm} / \mathrm{s}$. According to the codes of viscous fluid damper for bridges, the loading cases setting were shown in Table 1. Loaded by sine wave load with three cycles and the test results were shown in Fig 8 . The experimental data revealed that the push and pull axial force of eight single viscous dampers is lower than the $110 \%$ theoretical value and higher than the $90 \%$, which proved the rationality of the experiment and the velocity performance of the viscous dampers.

Table 1. Loading cases of tests

\begin{tabular}{cccccc}
\hline & $\mathrm{I}$ & $\mathrm{II}$ & $\mathrm{III}$ & $\mathrm{IV}$ & $\mathrm{V}$ \\
\cline { 2 - 6 } Case & $0.1 V_{\max }=$ & $0.25 V_{\max }=$ & $0.5 V_{\max }=$ & $0.75 V_{\max }=$ & $1.0 V_{\max }=$ \\
& $29 \mathrm{~mm} / \mathrm{s}$ & $72 \mathrm{~mm} / \mathrm{s}$ & $145 \mathrm{~mm} / \mathrm{s}$ & $217 \mathrm{~mm} / \mathrm{s}$ & $289 \mathrm{~mm} / \mathrm{s}$ \\
\hline
\end{tabular}



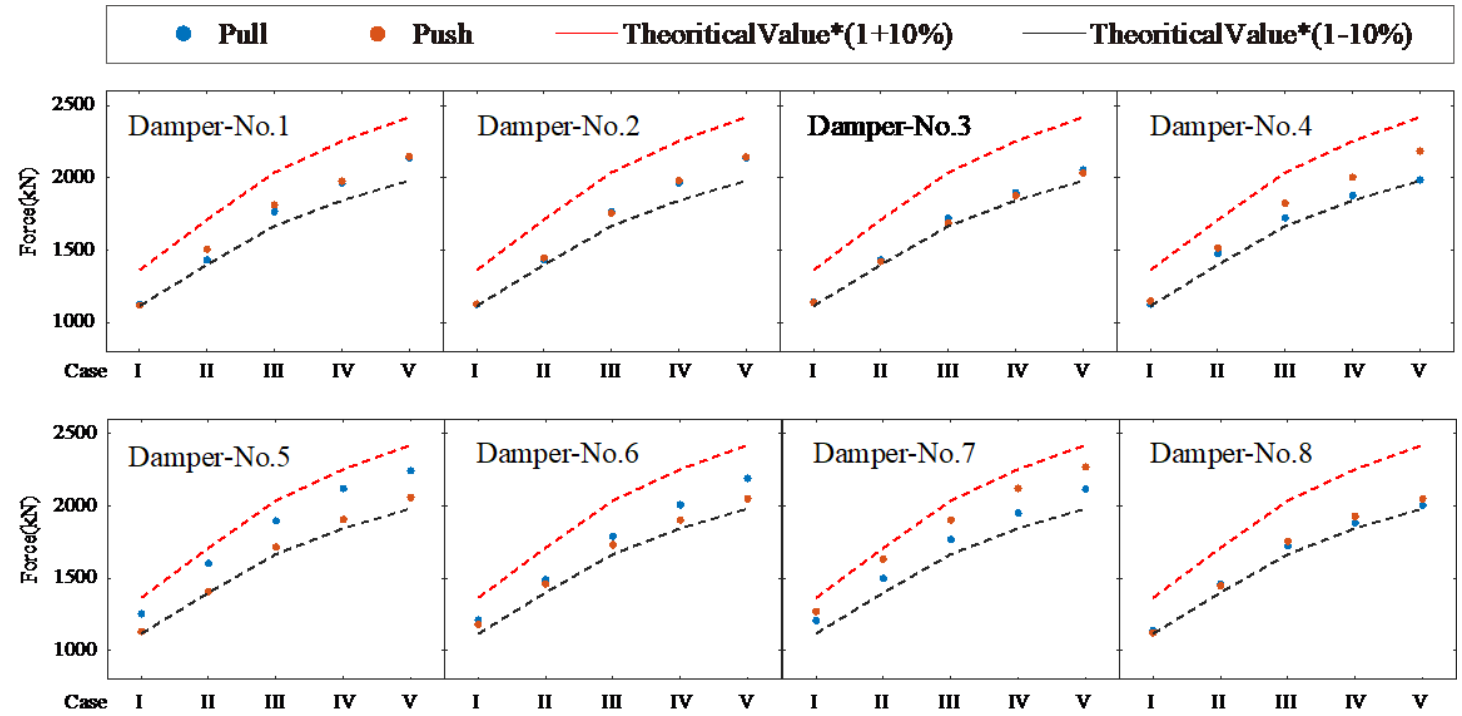

Fig 8. Performance test and results of viscous dampers under different loading velocity

Since the working path of the union-dampers structure is obviously different from that of the general single damper, a specific test platform ought to be designed to test the performance of the union dampers of MDDS. The schematic diagram of the platform structure is shown in the Fig 9(a) below.

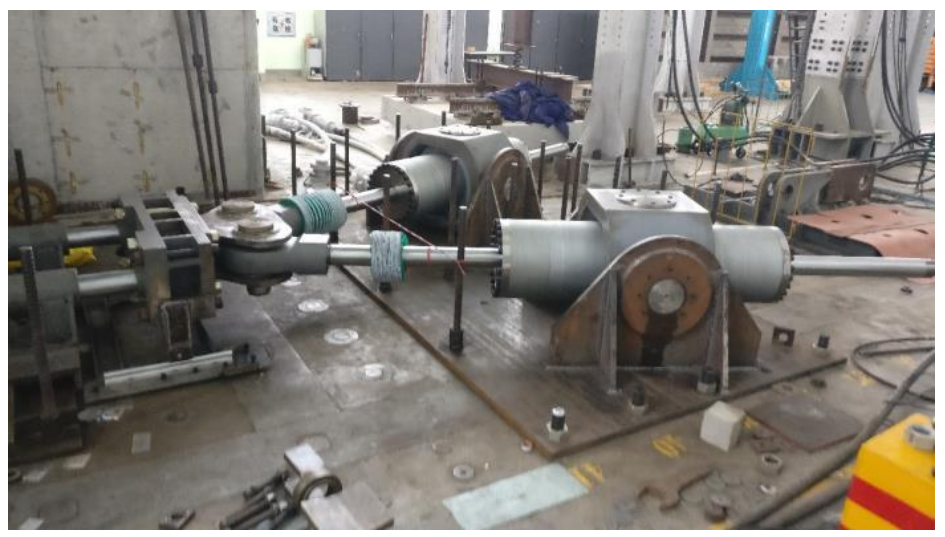

(a)
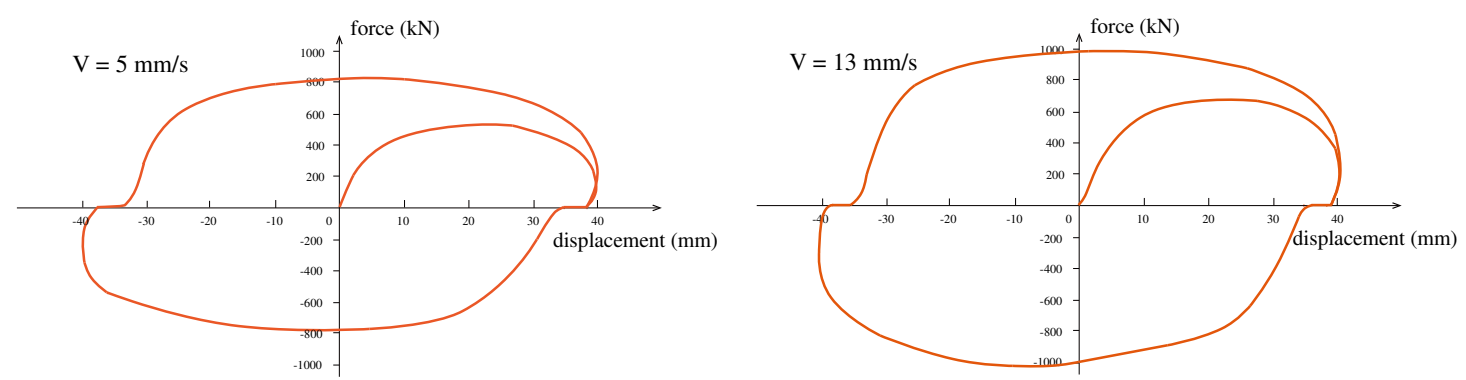

(b)

Fig 9. Union-dampers structure performance test: (a) test platform, (b) hysteresis curves of $5 \mathrm{~mm} / \mathrm{s}$ and $13 \mathrm{~mm} / \mathrm{s}$ loading

The relationship between force and displacement of the union-dampers structure under two 
slow loading conditions, namely, $5 \mathrm{~mm} / \mathrm{s}$ and $13 \mathrm{~mm} / \mathrm{s}$, were analyzed, and the force-displacement hysteretic curves of each case were shown in the Fig 9(b). As can be seen, the union-dampers worked smoothly in the loading process, and the overall hysteresis curve of the union-dampers were smooth and full, indicating a cooperative working state with reliable performance.

According to the above tests and results, the performance of viscous dampers on MDDS and the connecting component i.e. the universal hinge support were verified. Moreover, the union dampers structure also exhibited the high working efficiency, which can be further applied in the following study.

\section{Practical application and performance analysis}

\subsection{Bridge description}

The selected bridge in this article is a super-long column-pylon cable-stayed bridge which is located in China and equipped MDDS practically. The bridge has five spans with the 806 meters main span, and the bridge configuration is shown in Fig 10(a). With 25 stays in a fan configuration, altogether 100 stays in 4 fans are arranged. The girder is in the form of split amplitude, with a single width of 18 meters and a distance of 17 meters between the two separated beams which are connected by crossbeams, as shown in Fig 10(b).

A pylon is divided into three parts: lower pylon, middle pylon and upper pylon. The sections whose connect the lower-middle pylon and middle-upper pylon (section B-B, section C-C) are seen as the critical sections of the pylon. Meanwhile, the pylon bottom usually takes the first place of the most vulnerable sections under earthquakes. So, the bottom section (section A-A) is also deemed to be a key one, and three sections mentioned are depicted in Fig 10(c). The concrete of pylon is grade C50, and the HRB400 steel bars are equipped. The foundation of the pylon adopts circular cap, under which 30 bored piles are set, and the design of variable diameter pile is adopted. The group piles spacing is $6.0 \mathrm{~m}$.

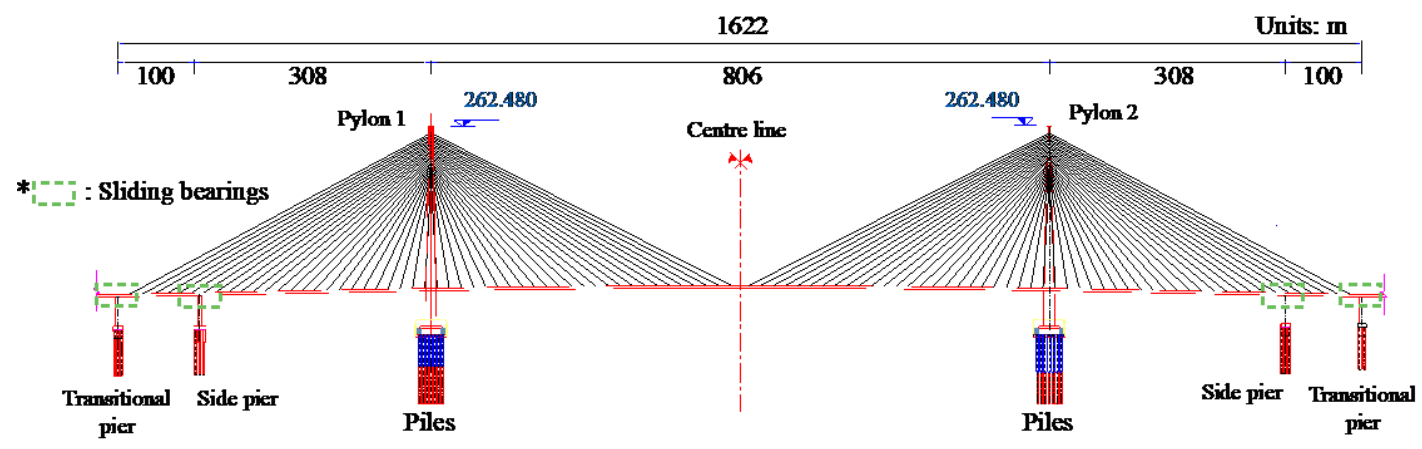

(a) 

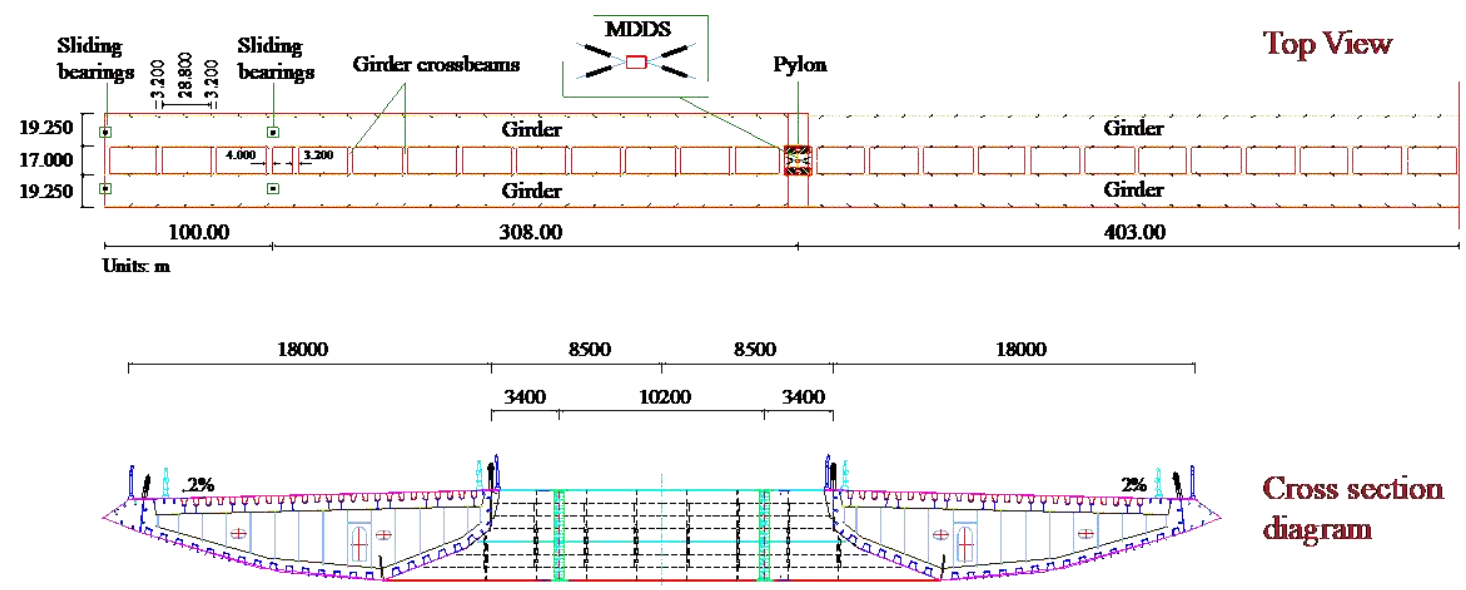

(b)

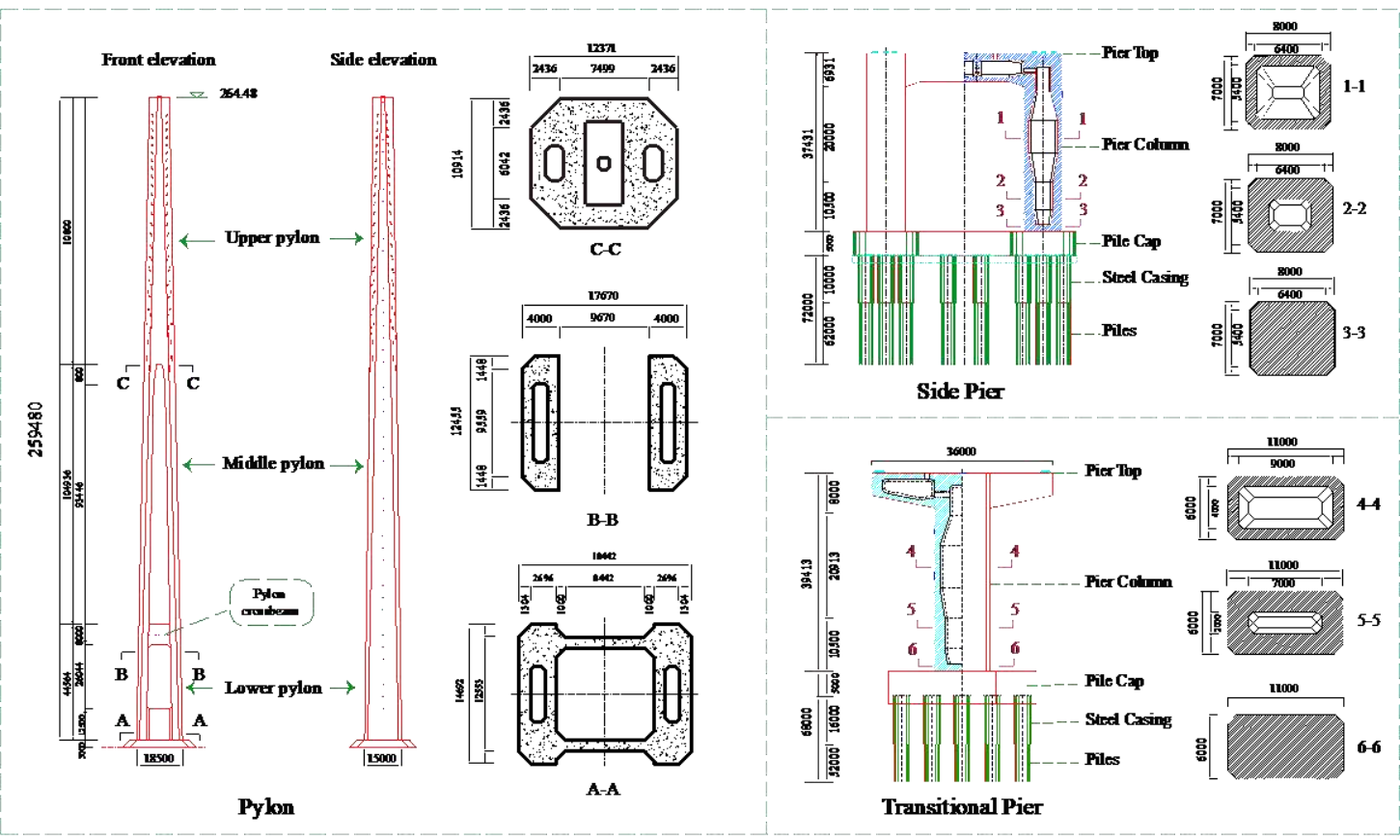

(c)

Fig 10. Bridge layout illustration: (a) bridge configuration, (b) top view of half bridge and cross section diagram of the girder, (c) pylon and piers configurations and key sections

The whole bridge contains two types of piers: side piers and transition piers (which are connected with approach bridge), respectively, and all adopts concrete of grade C40 with HRB400 steel bars inside. Side piers are arranged as T-shape single-column piers, with 42.18 meters high, setting a $11 \mathrm{~m} \times 6 \mathrm{~m}$ rectangular section. Thirteen bored piles with a diameter of $3.0 \mathrm{~m}$ are set with the pile cap covered. The transition pier is a double-column type pier with 33.9 meters height each single column and the section is an $8 \mathrm{~m} \times 7 \mathrm{~m}$ rectangular size. Five bored piles with a diameter of $3.0 \mathrm{~m}$ are set under each pier column and two piles are set under the collar beam. The minimum center distance between foundation piles of the piers is $6.0 \mathrm{~m}$. In view of the lower part of the pier is relatively vulnerable to damage in seismic actions, sections which located at the 
bottom, lower-part, middle part are shown with details in the Fig 11(c).

\subsection{Finite element modeling}

Based on the OpenSEES platform, a detailed finite element numerical model of the bridge is built and shown in Fig 11.

Under the earthquake actions, it is generally considered that the probability of damage to the bridge superstructure is low. Thus, this article assumes that the girder is always in the elastic state [30], and uses the elastic beam-column element to model. Ernst method or modified elastic modulus method can be used for the consideration of sag effect [31,32], so large-displacement truss element is adopted to simulate every cable.

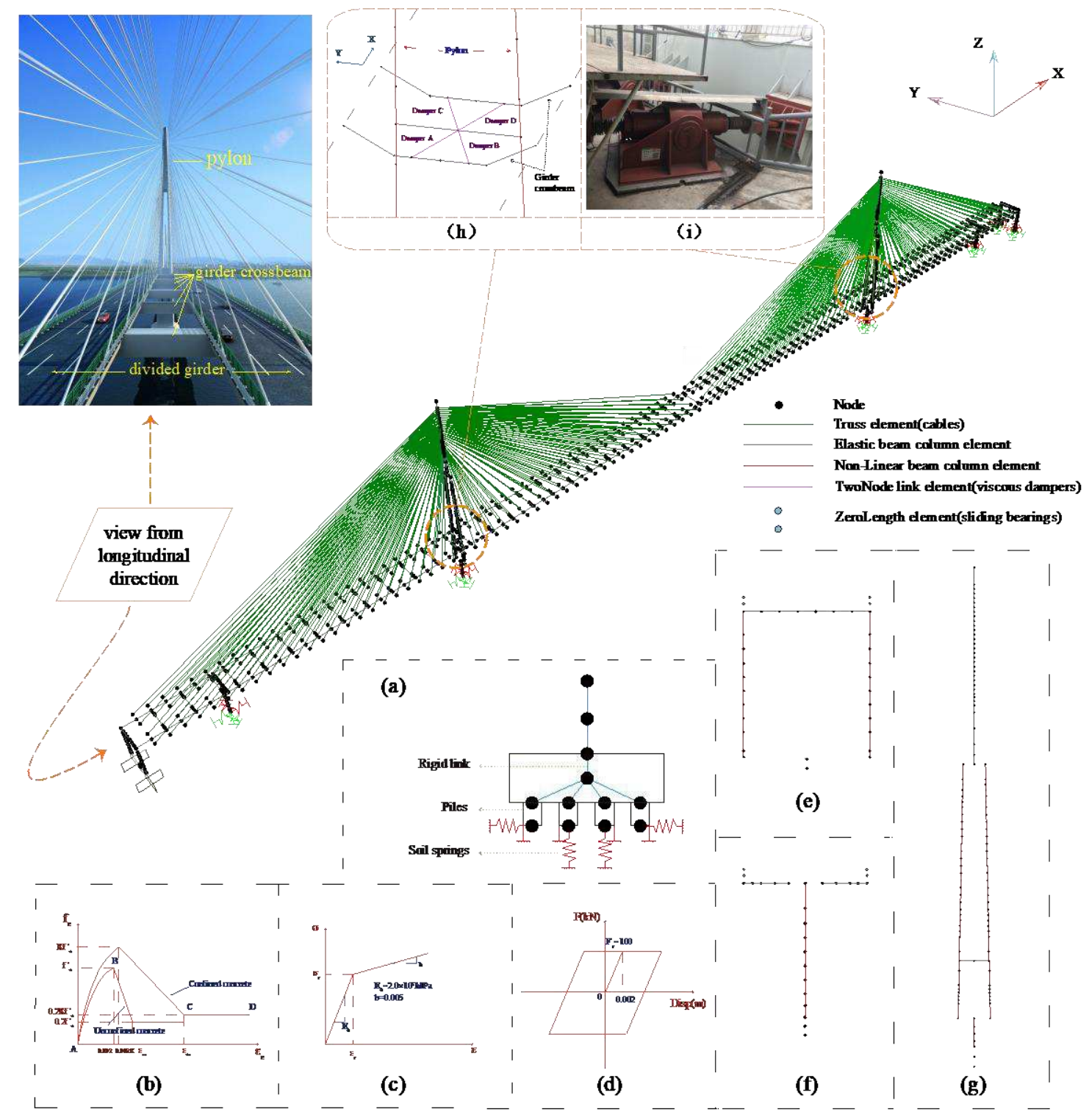

Fig 11. Bridge Finite Element Model: (a) soil springs simulation; (b) (d) force-displacement relationships of concrete, steel bars and bearings; (e) $\sim(g)$ finite element model of side pier, transition pier and pylon; (h) (i) finite 
element model and practical application of MDDS on the bridge

Through the non-linear element simulation, the soil-pile interactions are considered by using six soil springs which contains three translational ones and three rotational ones, are set at each bottom of the piers and pylons,as shown in Fig 11(a). Due to the bridge site which is mainly composed of silty clay, soft soil, fine sand, medium sand and pebble soil from above, the "m" method [33] is optimal for using to obtain the springs stiffness.

As the substructure of the cable-stayed bridge system tend to give non-linear behaviour under seismic actions [34], the non-linear beam-column elements are used to simulate piers, lower pylon and middle pylon. As the superstructure is often the last part to be damaged during earthquakes, the upper pylon is modeled by the elastic-beam column element under the supposition of its linear state. Sections of piers, lower and middle pylons are discretized into confined concrete, unconfined concrete and reinforced bar fibers, which are modeling by fiber sections [35]. In order to reflect the nonlinear characteristics of the material and the interaction effect of axial force-moment, the distributed models are used to represent the sections of lower, middle pylons and piers. Furthermore, this article uses a simplified bi-linear reinforced steel bars model considering the stiffness after yield, and the concrete stress-strain model adopts Kent-Scott-Park [36] model of Concrete01Material concrete in OpenSEES platform, as shown by Fig 11(b) to (c).

The sliding bearings are set on the piers top which can adapt to the structure displacement and deformation caused by the various load or temperature effect [37]. Through the simulation by using zero length element, and Elastic PP materials are using and given stiffness in three directions. The bearing model is shown in Fig 11(d). In particular, the MDDS is simulated as Two-Node link elements in this finite element model and adopts the unixialMaterial ViscousDamper as its material in OpenSEES. In addition to the damper setting parameters given above, the initial stiffness $\mathrm{K}$ is also set to simulate the series material, so that the structural period will not be significantly reduced, which is equivalent to pure damping.

\subsection{Seismic fragility analysis of the bridge with MDDS equipped}

\subsubsection{Fragility approach}

Through the previous study and calculation on seismic fragility analysis of structures, a set of analytical theories based on probability theory has been summarized. The concept of seismic fragility can be simply summarized as the failure probability of each component and system under earthquake actions. Fragility can be defined as the conditional probability that the seismic demand $(D)$ imposed on the structure exceeds its capacity $(C)$ under a given level of seismic intensity measure (IM). 


$$
F_{r}=P[D \geq C \mid I M]=P[D-C \geq 0 \mid I M]
$$

To derived the PSDM (probabilistic seismic demand model) which is capable of probabilistic estimation of EDPs (engineering demand parameters), Cornell [38] generalized the average demand of the structure under seismic action by the following Eq (9).

$$
\ln \left(S_{D}\right)=a \ln (I M)+b
$$

Where, $a$ and $b$ are statistical regression coefficients. In general, it can be assumed that both demand and capacity follow a logarithmic normal distribution, and the transcendental probability is derived in $\mathbf{E q ( 1 0 )}$ as followed.

$$
P[D \geq C \mid I M]=\Phi\left\{\frac{\ln \left(S_{D}\right)-\ln \left(S_{C}\right)}{\sqrt{\beta_{D \mid I M}^{2}+\beta_{C}^{2}}}\right\}
$$

Where, $\Phi(\mathrm{g})$ represents the standard cumulative normal-distribution function, $S_{D}$ and $\beta_{\mathrm{D} \mid \mathrm{IM}}$ are the median value of structure response and the logarithmic standard error; $S_{C}$ is the median value, $\beta c$ is the structural capacity dispersion, respectively. $\beta_{\mathrm{D} \mid \mathrm{IM}}$ calculation can be expressed as the following $\mathbf{E q ( 1 1 ) . ~}$

$$
\beta_{D \mid I M}=\sqrt{\frac{\sum\left[\ln \left(d_{i}\right)-\ln \left(S_{D}\right)\right]^{2}}{(n-2)}}
$$

The $d_{i}$ is the $i$ th simulation result of demands, and the $n$ represents the number of simulation. And the ultimate purpose of PSDM deduction is to obtain the relationship between peak seismic response and earthquake action intensity.

\subsubsection{Input ground motions}

In considering of the uncertainty of ground motions inputting [39], 100 ground motion records are selected in this study. 80 of them are chosen from PEER strong motion database with magnitude ranges from 5.8 to 6.9 , and the epicentral distance ranges from $10 \mathrm{~km}$ to $60 \mathrm{~km}$; The rest of records are selected from SAC engineering database which have $2 \%$ and $10 \%$ exceedance probabilities in 50 years. The magnitudes of 20 ground motions range from 6.0 to 7.0 , and the epicentral distance is less than $15 \mathrm{~km}$, of which the lowest is $2.5 \mathrm{~km}$. The PGV distribution of 100 selected records are shown by the size of points in Fig 12, the bigger point represents the higher PGV value. The ground motions are input into the model according to the directions. 


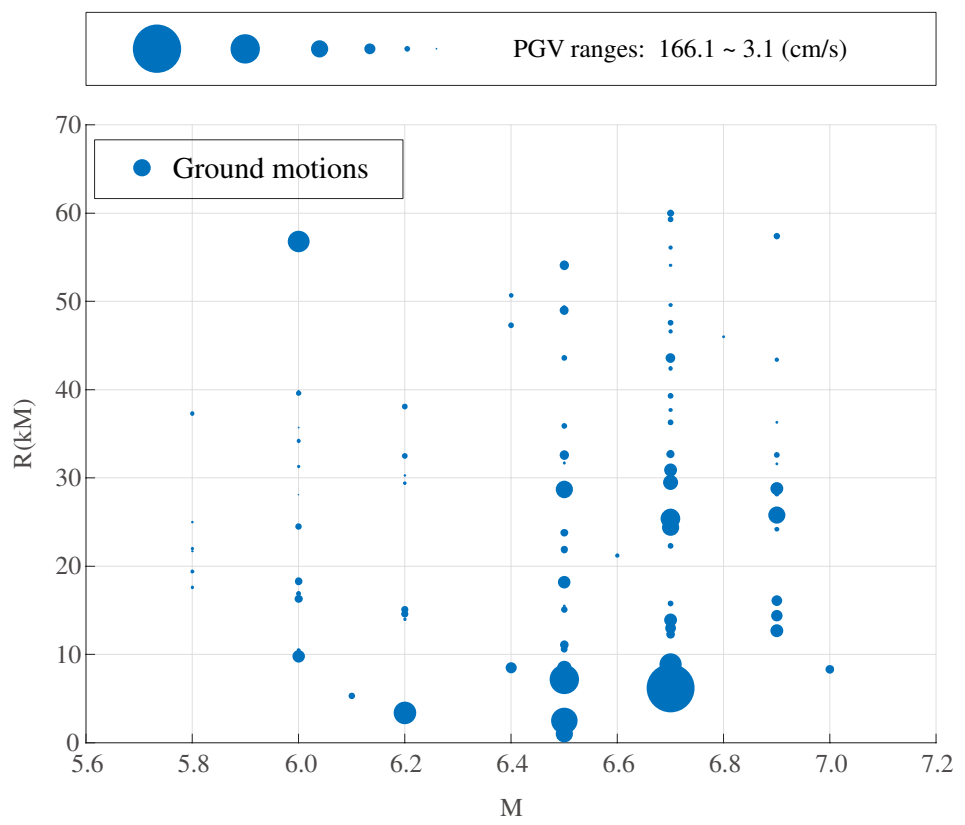

Fig 12. Epicentral distance, magnitude and PGV distribution of 100 ground motions

\subsubsection{Engineering demand parameters and damage states threshold}

Seismic fragility is the convolution of demand model and capability model. Defining EDPs ability and damage limit states is a indispensable step in generating fragility curves. In general, the substructure of a bridge is much more vulnerable to damage than its superstructure under earthquake action. Therefore, this article selected the transversal and longitudinal curvature ductility of the section 3-3 in a side pier, section 6-6 in a transition pier, and the section A-A, B-B, $\mathrm{C}-\mathrm{C}$ of one pylon which were shown in Fig 10(c). The displacements of two bearings on two piers and the displacement of MDDS on a single pylon which were defined by displacement-ductility ratio were also considered, a total of 13 EDPs were chosen and listed in the Table 2.

Table 2. Engineering demand parameters and damage states of various components

\begin{tabular}{|c|c|c|c|c|c|c|c|}
\hline \multicolumn{2}{|r|}{ EDP } & \multirow{2}{*}{$\begin{array}{l}\text { Direction } \\
\text { /Position }\end{array}$} & Abbreviation & DS-1 & DS-2 & DS-3 & DS-4 \\
\hline \multirow{8}{*}{$\begin{array}{l}\text { Sections } \\
\text { ( in Fig 11) } \\
\text { curvature }\end{array}$} & $3-3$ of SP & & $\mu_{\phi x-33}$ & 1 & 1.53 & 5.75 & 51.89 \\
\hline & 6-6 of TP & & $\mu_{\phi x-66}$ & 1 & 1.50 & 4.72 & 52.82 \\
\hline & A-A of pylon & Longitude & $\mu_{\phi x-\mathrm{AA}}$ & 1 & 1.44 & 4.06 & 9.93 \\
\hline & B-B of pylon & & $\mu_{\phi x-\mathrm{BB}}$ & 1 & 1.51 & 4.48 & 12.81 \\
\hline & C-C of pylon & & $\mu_{\phi x-C C}$ & 1 & 1.51 & 4.02 & 12.83 \\
\hline & $3-3$ of SP & & $\mu_{\phi y-33}$ & 1 & 1.51 & 4.83 & 41.43 \\
\hline & 6-6 of TP & Transverse & $\mu_{\phi y-66}$ & 1 & 1.47 & 4.21 & 39.25 \\
\hline & A-A of pylon & & $\mu_{\phi y-\mathrm{AA}}$ & 1 & 1.26 & 4.58 & 10.31 \\
\hline
\end{tabular}




\begin{tabular}{|c|c|c|c|c|c|c|}
\hline B-B of pylon & & $\mu_{\phi y-\text { вв }}$ & 1 & 1.22 & 4.45 & 12.55 \\
\hline C-C of pylon & & $\mu_{\phi y-C C}$ & 1 & 1.50 & 4.64 & 10.50 \\
\hline \multirow{3}{*}{ Sliding bearing displacement } & Side pier & $\delta_{\mathrm{B}-\mathrm{SP}}$ & \multirow{3}{*}{1} & \multirow{3}{*}{2} & \multirow{3}{*}{-} & \multirow{3}{*}{-} \\
\hline & & & & & & \\
\hline & pier & $\delta_{\mathrm{B}-\mathrm{TP}}$ & & & & \\
\hline Damper displacement & Pylon-Girder & $\delta_{\mathrm{DP}}$ & 1 & 2.5 & - & - \\
\hline
\end{tabular}

Note: SP and TP represent side pier and transitional pier respectively.

The recorded engineering demand parameters need certain quantitative indicators to evaluate their damage status. Side piers, pylons and transition pier can be regarded as components mainly composed of concrete. For the definition of damage state of concrete members, pioneers have done a lot of research work, and put forward a variety of evaluation indexes $[40,41,42,43,44]$. In this article, the damage states [45] are defined as four levels i.e. slight (DS1), moderate (DS2), extensive (DS3), and complete (DS4). the pushover analysis of three kinds of concrete members is carried out by OpenSEES. In order to facilitate calculation and comparison, the value of DS-1 of selected components is normalized, and the ratio is used to reflect the quantitative relationship between various damage states, which are listed in the Table 2.

Sliding bearing and viscous damper dissipate huge energy mainly by their own displacement in earthquake action, thus generally using the ratio of displacement and ductility to evaluate their damage status. The bearing used in this article is bidirectional sliding spherical steel bearing, and its design displacement is $\pm 300 \mathrm{~mm}$, so half of the design displacement, i.e. $\pm 150 \mathrm{~mm}$ is regarded as slight damage state, and the design displacement is regarded as moderate damage state.

If the damping effect of the viscous damper on the dynamic response is taken into account, the response of the structure under wind load will not exceed the reserved clearance, so the influence of wind load on the bridge does not need to be considered when designing the damping parameters. According to the relative displacement of pylon-girder does not exceed the reserved clearance of $200 \mathrm{~mm}$ and $500 \mathrm{~mm}$ under E1 earthquake in transversal direction and E2 earthquake in longitudinal direction respectively, the threshold of slight damage and moderate damage is defined as $200 \mathrm{~mm}$ and $500 \mathrm{~mm}$.

Due to the bearings and dampers are non-critical components, their failure will not lead to serious damage or even collapse of the cable-stayed bridge structure, so this article only defines the slight (DS-1) and moderate (DS-2) damage status of them, which are shown in Table 2.

\subsubsection{Fragility curves of critical components}

In previous studies, a number of intensity measures (IMs) [46] have been investigated and 
adopted. Wei et al. [47] and Zhong et al.[48,49] put forward that peak ground velocity (PGV) is the IM which was seen as the optimum selection for the multi-pylon cable-stayed bridges. Thus, PGV was chosen to simulate the PSDMs of 13 EDPs through Eq (8), (9), (10) in this section, for which effect can confirm above achievements were applicable to this research bridge structure. And the PSDMs of 13 selected EDPs on PGV are shown below in Fig 13.

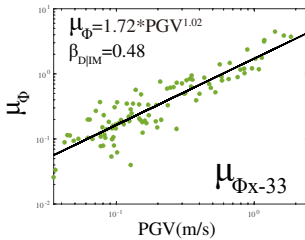

(a)

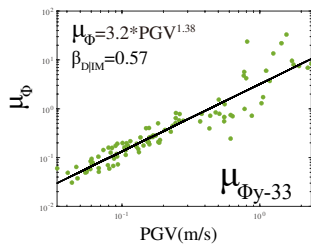

(f)

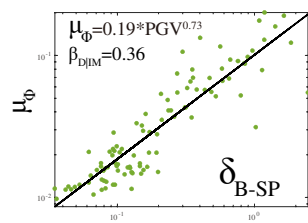

$(\mathrm{k})$

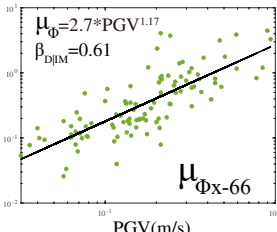

(b)

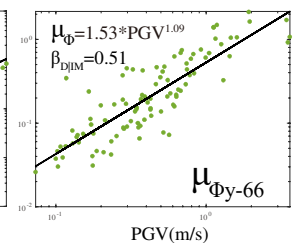

(g)

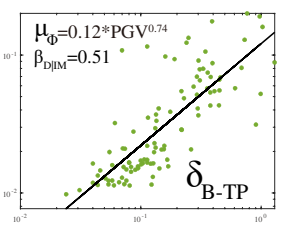

$\mathrm{PGV}(\mathrm{m} / \mathrm{s})$

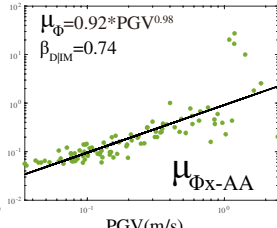

(c)

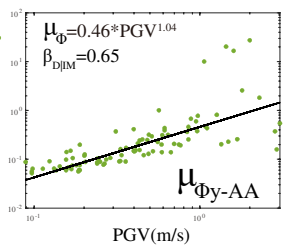

(h)

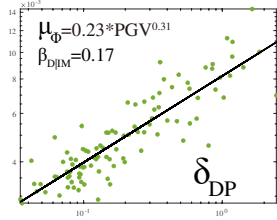

$\mathrm{PGV}(\mathrm{m} / \mathrm{s})$

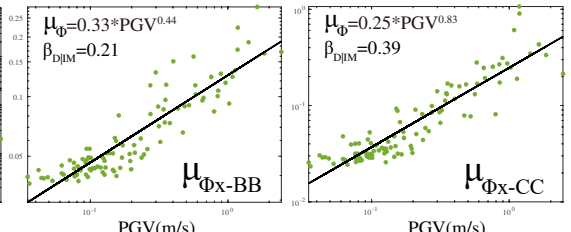

(d)

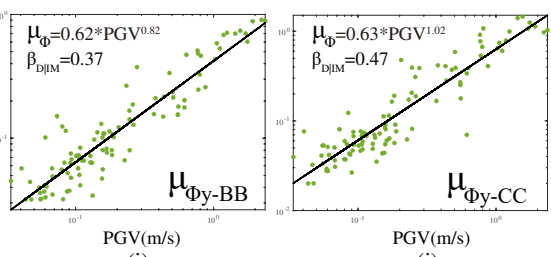

(i)

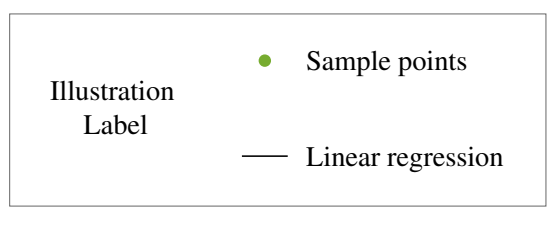

Fig 13. PSDMs for 13 EDPs on PGV

Through the selection of EDPs, the comparison of IM and the fitting of PSDM above, the fragility curves of each component were obtained, as shown in Fig 14. In the figure, four lines from top to bottom represent four failure states of DS-1, DS-2, DS-3 and DS-4, respectively. Fig (a) and Fig (f) show that the transverse(y direction) failure probability of the side piers of the full bridge model equipped with MDDS is greater than that of the longitude(x direction), while the situation of the transition piers is just the same, as shown in Fig (b) and Fig (g). Fig (c) (e), $\operatorname{Fig}(\mathbf{h}) \sim(\mathbf{j})$ have shown the fragility in both direction of pylon bottom section (section A-A), the joint-part section between column and crossbeam where MDDS arranged (section B-B) and the section which links middle-column and upper-column (section C-C): the DS-1 and DS-2 curves of section A-A are closer both in transversal and longitudinal direction between 0 to $1.0 \mathrm{~m} / \mathrm{s}$. On the other hand, in section B-B, the DS-1 is similar from the former, but the upward trend of DS-2 is relatively slower. The corresponding PGV of section C-C which at the top of the selected elements, with a $50 \%$ probability of reaching DS-1, is more than twice that of the first two sections. A comparison of median values is shown in the histogram.In view of the curve characteristics of all the above ductility sections, under the same PGV, the failure probability of components in the longitudinal direction is always smaller than that in the transversal direction. 
The fragility of the sliding bearings at the side pier and the transition pier are shown in Fig (k) and Fig (l). It is found that within $2.0 \mathrm{~m} / \mathrm{s}$, the bearings are almost impossible to reach the state of moderate damage, and the same is true of the single-unit damper of MDDS, the failure probability will not exceed 20\% when PGV reaches $2.0 \mathrm{~m} / \mathrm{s}$, as shown in Fig (m). Therefore, the bearings and dampers can be regarded as relatively safe components under earthquake actions.

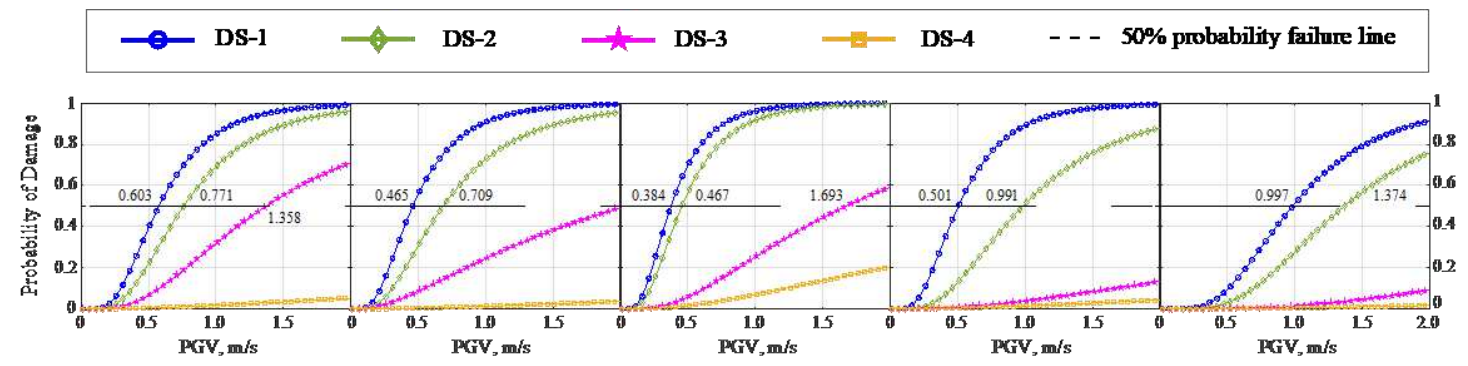

(a) $\mu_{\Phi \times-33}$

(b) $\mu_{\Phi_{\mathrm{X}}-66}$

(c) $\mu_{\Phi \mathrm{Qx} A \mathrm{~A}}$

(d) $\mu_{\Phi \mathrm{x}-\mathrm{BB}}$

(e) $\mu_{\Phi \mathrm{x}-\mathrm{CC}}$

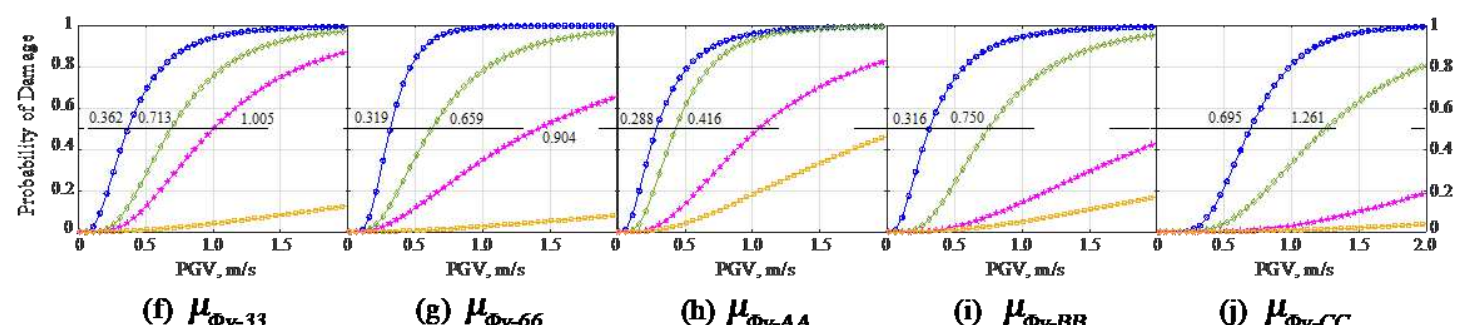

(f) $\mu_{\Phi y-33}$

(g) $\mu_{\Phi y-66}$

(h) $\mu_{\text {Фy-AA }}$

(i) $\mu_{\Phi y-B B}$

(j) $\mu_{\Phi y-C C}$

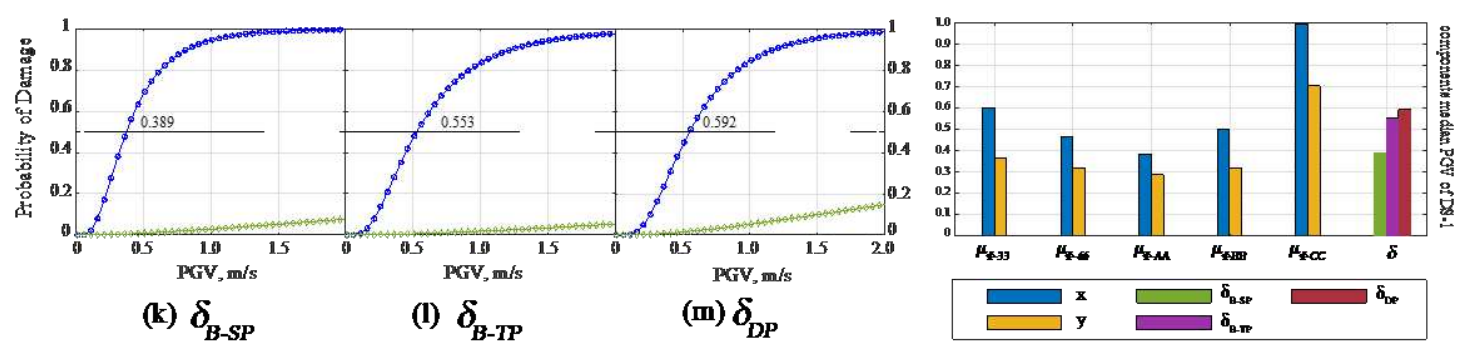

Fig 14. Exceeding probabilities of components under different damage states

\subsection{Evaluation on seismic performance of MDDS}

In order to testify the MDDS working performance in both longitudinal and transversal directions under seismic actions, three other different cases were set for comparison in this article, i.e., Transversal Damping System (TDS), Longitudinal Damping System (LDS) and Bidirectional Damping System (BDS), as shown in Fig 15. In addition to the different way of damper arrangement, the damping coefficient $C_{t}$ of TDS and $C_{l}$ of LDS are set according to Eq (6), (7) to ensure the control of variables and the accuracy of the results.

By inputting the same ground motions, the responses of each component under different cases are obtained. In this article, the responses of altogether 70 non-linear elements of the pylon were selected and their fragility were analyzed and obtained. For the symmetry structure only the 
elements on one side are considered, i.e., the ductility section of 35 non-linear elements. The PGV values of the fragility curves corresponding to the $50 \%$ probability of slight damage and extensive damage were extracted, and the median value graphs of the pylon were drawn, as shown in Fig 16.

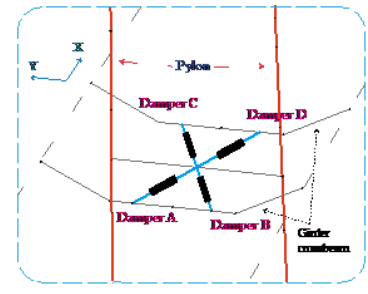

MDDs

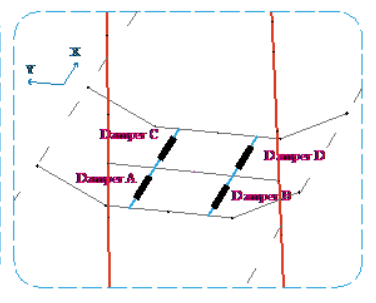

LDS

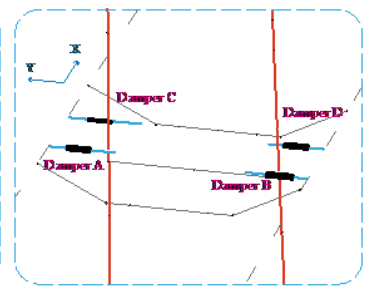

TIDS

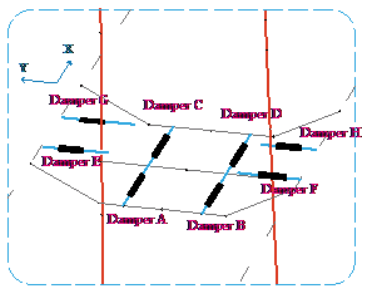

BDS

Fig 15. Setting schemes of viscous dampers

In the case of which the entire bridge equipped with MDDS, the dark blue lines in Fig $\mathbf{1 6}$ show the median PGV values in longitudinal and transversal directions, respectively. As can been seen,the median PGV lines in Fig 16(a) and (b) have similar distribution and trend from bottom to top. In each direction, the values corresponding to the damage probability from the bottom (Ele 5) to the cross beam (Ele 12) of the pylon increases first and then decreases, and values of elements above cross beam from Ele 13 to Ele 27 began to show a sustained growth trend. Then, both longitudinally and transversely,the trend tend to be flat from Ele 27 until Ele 32. Finally, from Ele 32 to the top of the middle pylon i.e. Ele 39, the values show continuous declination. The graphs also tells that the section A-A, section B-B and section C-C are the relatively most vulnerable ones of the pylon sections, which proves the reliability of selecting the three sections as key research objects in the previous analysis. 


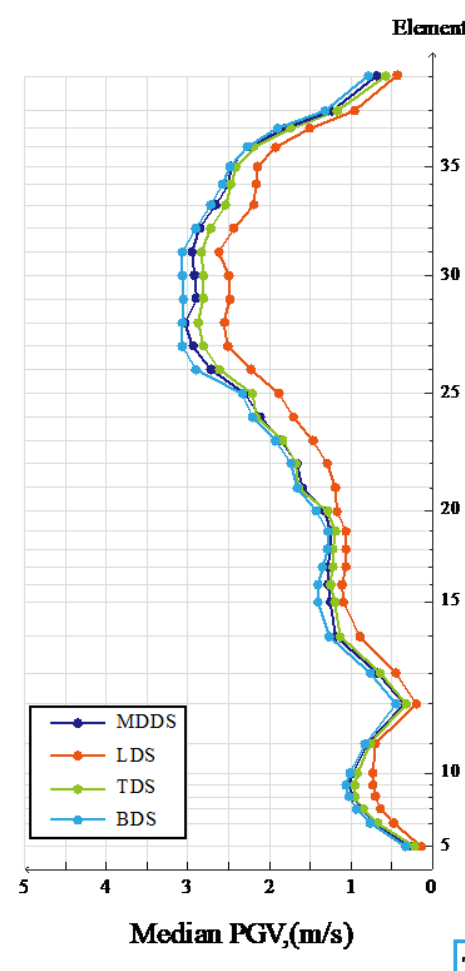

Transverse

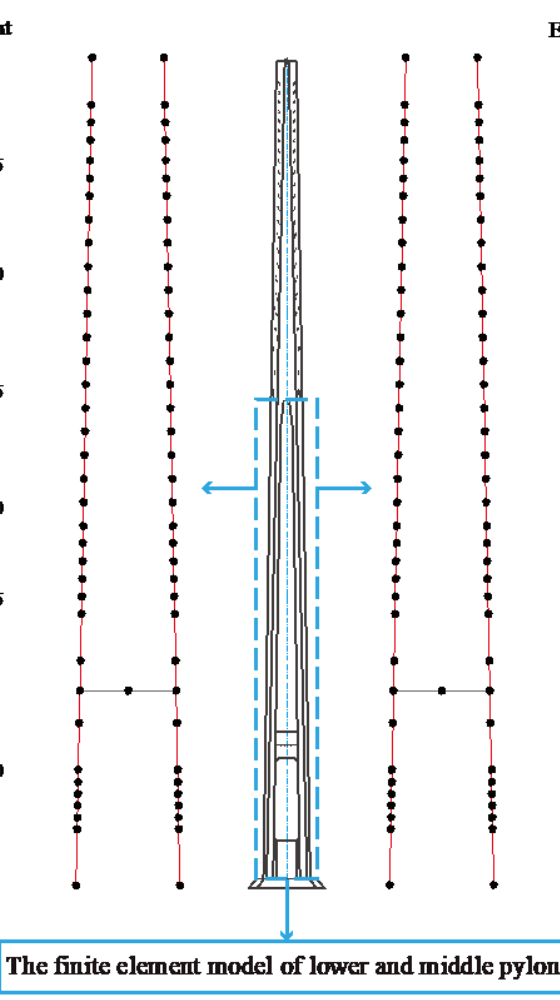

Element

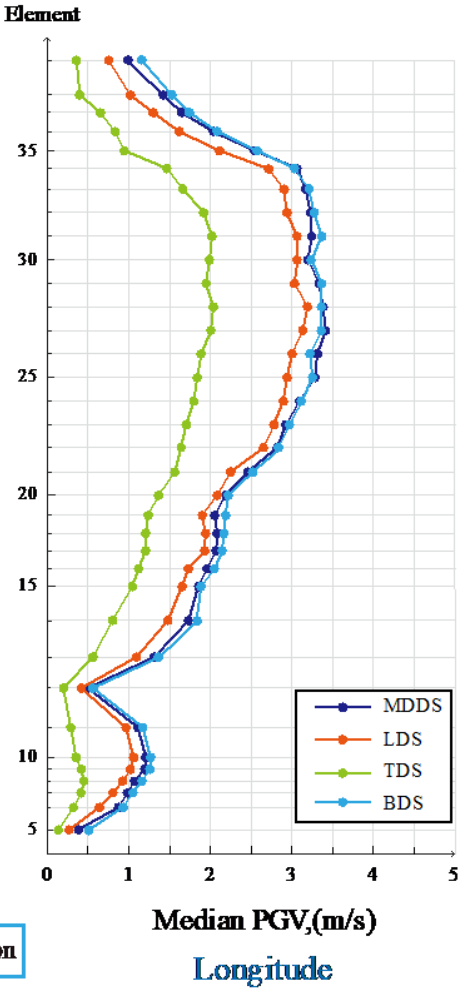

(a)

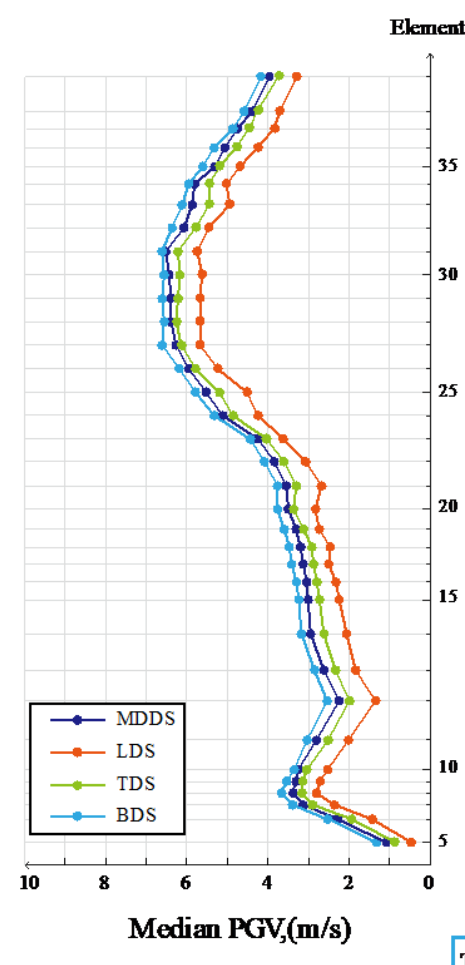

Transverse
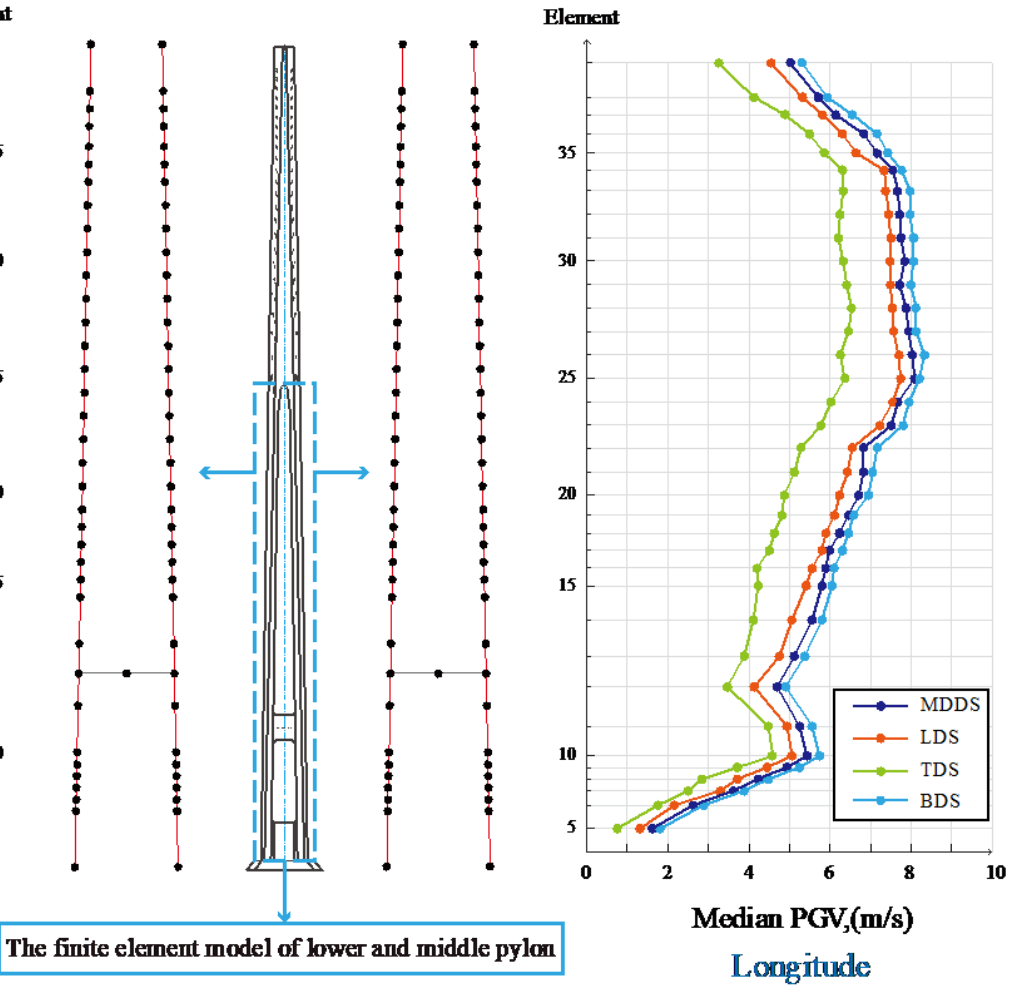

(b)

Fig 16. The median fragility value of pylon non-linear elements: (a) slight damage (DS-1); (b) extensive damage (DS-3)

Meanwhile, the other three lines in the figure respectively reflect the influence of the rest of 
damping systems on seismic fragility: Transversely, the LDS whose dampers were only set in the longitudinal direction is undoubtedly the worst damping solution. Similarly, TDS made the least contribution in longitudinal direction. In each of two direction, the dark blue lines representing MDDS and the light blue lines representing BDS have nearly the same distribution and trend. It can be indicated that MDDS achieves the seismic performance and damping effect as BDS with the premise of setting half number of dampers. What's more, it further verified the equivalent design method is applicable in the dynamic model. In contrast, the LDS and TDS scheme with dampers setting only in one direction make decent seismic performance only in their own direction, and are not better than MDDS scheme. Moreover, the lines tell that the effect of the damper is more pronounced in the longitudinal direction than in the transversal direction.

\subsection{Investigation on effect of MDDS installing angle on seismic performance of bridge system}

As the above evaluation only selects the fragility of pylon non-linear elements as the evaluation index, system-level fragility analysis is considered to carry out for it is able to further provide the comprehensive results. Due to space limitation, under the four damping cases mentioned above, the system-level fragility curves in slight damage and extensive damage will be given directly [50, 51], as shown in Fig 17.

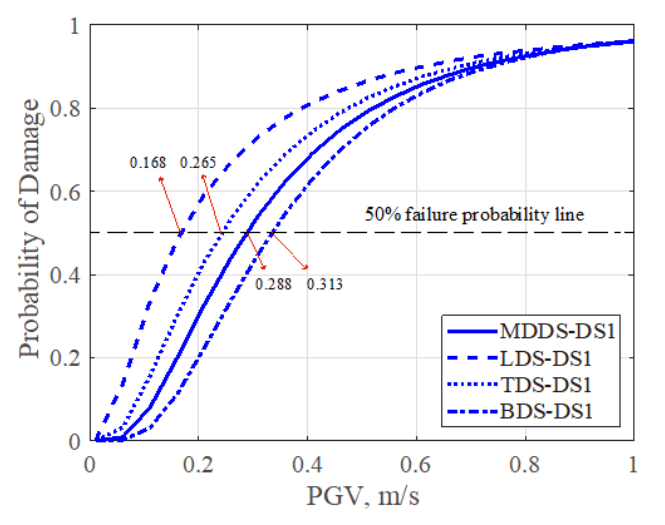

(a)

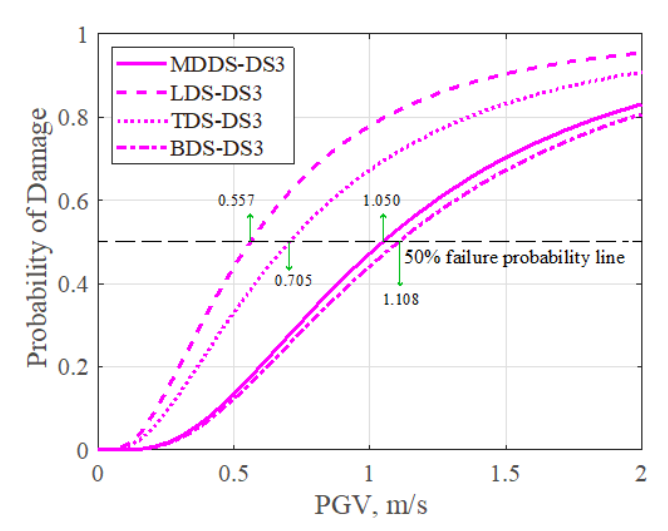

(b)

Fig 17. System-level exceeding probabilities under different damage states with four damping cases:(a) DS1, (b) DS3

Though the comparison of the system fragility curves under the four cases set in Fig 15, as shown in Fig 17, it is verified MDDS makes the best effect at the system level. Fig (a) and Fig (b) respectively represent the fragility curves of DS-1 and DS-4 states in different scheme cases. LDS takes the last place in either states while BDS takes the first one due to its sufficient number of dampers. However, MDDS exhibits the indistinguishable line tendency with BDS. To sum up, 
MDDS contributes similarly with BDS in reducing the failure probability of the system, which verifies the global working performance and efficiency of itself.

In order to explore the influence of different installation angles on the whole system of MDDS under earthquake actions, the different angle setting needs to be discussed and compared. The installation angle of MDDS is the included angle between the single-unit viscous damper and the longitudinal direction of the bridge. In this article, the default initial installation angle is $25^{\circ}$, and five other installing angle cases are set, as shown in Fig $\mathbf{1 8 .}$
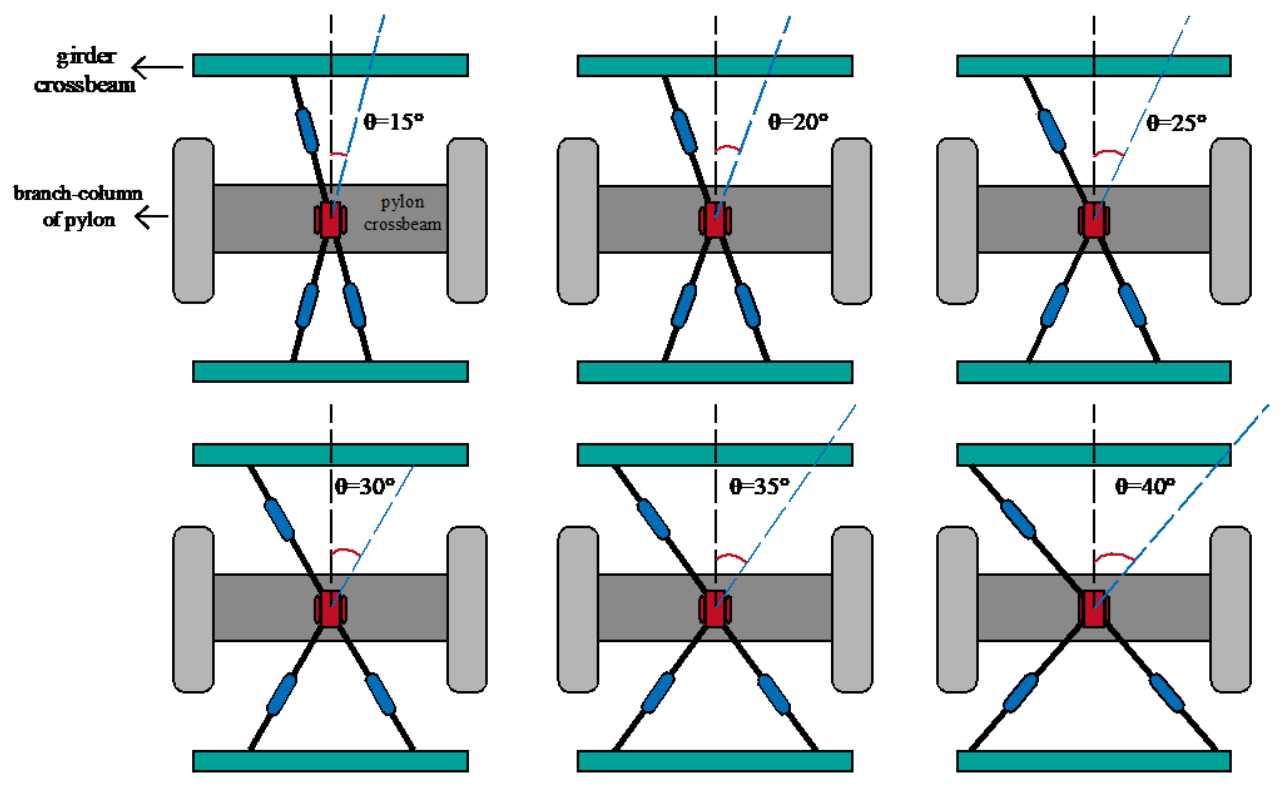

Fig 18. Various installation angle cases setting of MDDS

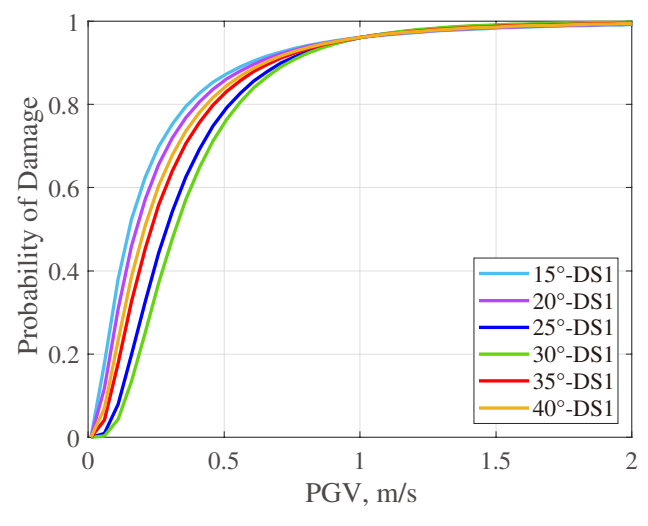

(a)

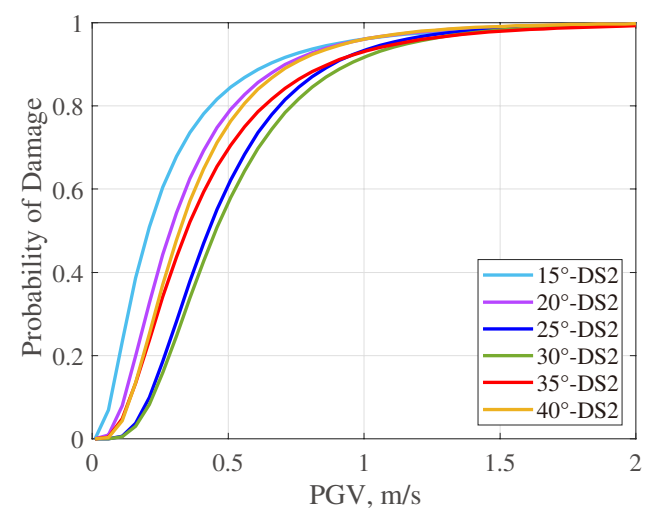

(b) 


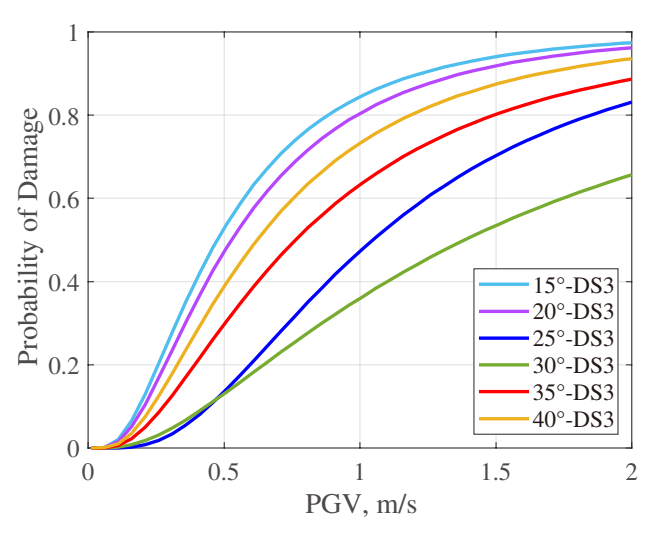

(c)

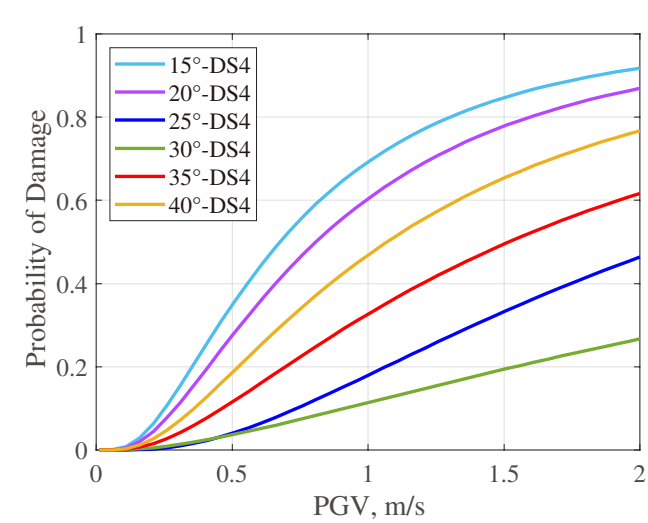

(d)

Fig 19. Effect of installation angle of MDDS on system fragility

System-level fragility is still used to evaluate various installation angles setting, as shown in Fig 19, which shows the impact of MDDS on system fragility at 6 installation angles cases. From DS- 1 to DS-4, the light blue line representing the $15^{\circ}$ case is at the far left of the line frame, that is, when the installation angle is 15 degrees, the probability of system damage is the highest; Similarly, the green line representing the $30^{\circ}$ case is always at the far right of all the lines, indicating that this angle of installation will make the bridge system least vulnerable to damage. As the installation angle increases from $15^{\circ}$ to $30^{\circ}$, the operating performance of MDDS reaches the best. Then the installation angle continues to increase, the operating performance begins to weaken, namely, the damage probability of the system being protected from failure is gradually reduced. However, the performance of $40^{\circ}$ is still better than that of $15^{\circ}$ and $20^{\circ}$. This analysis indicates that $30^{\circ}$ is the best installation angle for MDDS while $15^{\circ}$ is the worst, but only for this bridge case. Other bridge cases requiring the installation of MDDS ought to be analyzed separately.

\section{Conclusions}

Conventional damping arrangement is often only considered in longitudinal direction while transversal arrangement scheme is relatively lacking. Meanwhile, the traditional damper installation method has the risk of axial instability and the limitation of unidirectional loading only. This study proposed and investigated a new type multi-direction damping system i.e. MDDS which consists of multiple viscous dampers connected by a special connecting structure. Based on the support of engineering performance tests and equivalent design, this article simulated the installation of MDDS on a super-long span cable-stayed bridge by finite element numerical modeling, and assessed its influence through seismic fragility analysis. Moreover, MDDS was compared with other three dampers arranging cases to verify whether it has superior working 
performance. The results are as follows:

1) By installing universal hinge support as the central supporting member, MDDS overcomes the defects of axial instability of general dampers structure design. And the oblique combination leaded the system was able to reduce responses both in transversal and longitudinal direction. The engineering experimental test results and constitutive relation curve exhibited MDDS practical performance, and the equivalent design method which was proposed through mechanics relations was convinced.

2) Through seismic fragility analysis of the full bridge finite element model, the damage probability of selected sections (concrete members) is greater in transverse than that in longitude, and the pylon bottom section (A-A) was most vulnerable while the top section (C-C) of middle pylon was the opposite one; Sliding bearings and viscous dampers are relatively seen as the safer components of all in this study.

3) From the component-level fragility analysis, by comparing the median PGV of 35 non-linear elements of the pylon under four damping schemes, it was found that MDDS and BDS made the greatest seismic devotion whether in two directions. LDS and TDS contributed favourable performance only in their axial direction, while took the last place in the orthogonal direction. Meanwhile, from the system-level evaluation, MDDS ranks only second to BDS under four damage states. However, MDDS was considered to be the optimal case due to the same effect of BDS under the premise of without increasing the number of dampers.

4) In the comparative analysis of six installation angles cases, 30 degrees was identified as the best design installation horizontal angle for the MDDS of the bridge example studied in this article by comparing the system-level fragility curves.

\section{Acknowledgements}

This work is funded by the National Natural Science Foundation of China (52178135), the Fundamental Research Funds for the Central Universities of China (JZ2020HGTB0064). The supports are gratefully acknowledged.

\section{References}

[1] Han Q, Wen J, Du X, Huang C. Seismic response of single pylon cable-stayed bridge under scour effect. J Bridge Eng, 2019; 24(6).

[2] Ahad J, Khaled G, Zainah I, Huang F, Mieczysław K, Alireza T, Hamid M. Pounding mitigation of a short-span cable-stayed bridge using a new hybrid passive control system, Engineering Analysis with Boundary Elements, 2022; 134:625-636.

[3] Bruneau M. Performance of steel bridges during the 1995 hyogoken-nanbu (Kobe, Japan) 
earthquake—a North American perspective. Eng Struct, 1998; 20(12):1063-1078.

[4] Li B, Bi K, Chouw N, Butterworth JW, Hao H. Effect of abutment excitation on bridge pounding. Eng Struct, 2013; 54:57-68.

[5] Siringoringo D, Fujino Y, Namikawa K. Seismic response analyses of the Yokohama Bay cable-stayed bridge in the 2011 Great East Japan Earthquake. J Bridge Eng, 2013;19(8):1-17.

[6] Yan D, Yuan WC. Conceptual Seismic Design for Long-span Cable-stayed Bridges. Journal of Tongji University, 2004; 32(10):1344-1348.

[7] Li JZ, Guan ZG, et al. Lateral Isolation System of a Long-Span Cable-Stayed Bridge with Heavyweight Concrete Girder in a High Seismic Region. J Bridge Eng, 2017; 22(1):4016104.1.

[8] Calvi G M, Sullivan T J, Villani A. Conceptual Seismic Design of Cable-Stayed Bridges. J Bridge Eng, 2010; 14(8):1139-1171.

[9] Mirtaheri M, Samani HR, Zandi AP. The study of frictional damper with various control algorithms. Earthq Struct, 2017; 12(5):479-487.

[10] Zhong J, Hu ZL, Yuan WC, et al. System-based probabilistic optimization of fluid viscous dampers equipped in cable-stayed bridges. Adv Struct Eng, 2018; 21(12):1815-1825.

[11] Wei B, Hu ZL, He XH, et al. System-based probabilistic evaluation of longitudinal seismic control for a cable-stayed bridge with three super-tall towers. Eng Struct, 2021; 229:111586.

[12] Wada A, Huang Y, Bertero VV. Innovative Strategies in Earthquake engineering, Earthquake Engineering from Engineering Seismology to Performance-Based Engineering. 2004.

[13] Camara A, Cristantielli R, Astiz MA, et al. Design of hysteretic dampers with optimal ductility for the transverse seismic control of cable-stayed bridges. Earthquake Engineering \& Structural Dynamics, 2017; 46(11).

[14] He JH, Xu L, Yuan WC, et al. Transverse Seismic Design of Asymmetric Single Tower Cable-Stayed Bridge Under Strong Earthquake Excitations. 2018 3rd International Conference on Smart City and Systems Engineering (ICSCSE). 2018.

[15] Shen X , Camara A, Ye AJ . Effects of seismic devices on transverse responses of piers in the Sutong Bridge. Earthquake Engineering and Engineering Vibration, 2015; 14(4): 611-623.

[16] Guan ZG, Li JZ, and Yan X. Performance Test of Energy Dissipation Bearing and Its Application in Seismic Control of a Long-Span Bridge. J Bridge Eng, 2010; 15(6): 622-630.

[17] Niu J, Ding Y, Shi Y, et al. Oil damper with variable stiffness for the seismic mitigation of cable-stayed bridge in transverse direction. Soil Dynamics and Earthquake Engineering, 2019;125(Oct.):105719.1-105719.15.

[18] Zhang C, Wen JJ, Han Q, et al. Transverse seismic response of diamond-shaped pylon in cable-stayed bridge: Experiment and analysis. Eng Struct, 2022; 250:113414.

[19] Guan ZG, You H, Li JZ. An effective lateral earthquake-resisting system for long-span 
cable-stayed bridges against near-fault earthquakes. Eng Struct, 2019; 196(OCT.1):109345.

[20] Zhou LX, Wang XW, and Ye AJ. Shake table test on transverse steel damper seismic system for long span cable-stayed bridges. Eng Struct, 2019; 179:106-119.

[21] Xie W, and Sun L. Passive hybrid system for seismic failure mode improvement of a longspan cable-stayed bridges in the transverse direction. Adv Struct Eng, 2014; 17(3): 399-411.

[22] Xie W, and Sun L. Experimental and numerical verification on effects of inelastic tower links on transverse seismic response of tower of bridge full model. Eng Struct, 2019; 182(MAR.):1344-362.

[23] Infanti S, Papanikolas P, Theodossopoulos G. Rion-Antirion bridge: full-scale testing of seismic devices. 2003.

[24] Hwang H, Jaw J. Probabilistic Damage Analysis of Structures. J Struct Eng, 1990; 116(7):1992-2007.

[25] Ellingwood B R. Earthquake risk assessment of building structures. Reliability Engineering \& System Safety, 2001; 74(3):251-262.

[26] Ellingwood B R. The role of risk assessment in performance-based engineering. 2009.

[27] Pang YT, Zhou XY, He W, Zhong J, Hui OY. Uniform design-based gaussian process regression for data-driven rapid fragility assessment of bridges, Journal of Structural Engineering, 2021, 147(4): 0-04021008.

[28] Narges AK, Mohammad CB, Mohammadreza C. Multi-objective optimum design of nonlinear viscous dampers in steel structures based on life cycle cost. Structures, 2021; 34:3776-3788.

[29] E Buckingham. On physically similar systems; illustrations of the use of dimensional equations. Phys Rev, 1914; 4 (4): pp. 345-376.

[30] Li C, Li HN, Hao H, Bi KM, et al. Seismic fragility analyses of sea-crossing cable-stayed bridges subjected to multi-support ground motions on offshore sites. Eng Struct, 2018; 165:441-456.

[31] Hyeon Cheol Jo, Soo Hyung Kim, Jisang Lee, Hong-Gyoo Sohn, Yun Mook Lim, Sag-based cable tension force evaluation of cable-stayed bridges using multiple digital images. Measurement, $2021 ; 186: 110053$

[32] Pang YT, Wu X, Shen GY, and Yuan WC. Seismic fragility analysis of cable-stayed bridges considering different sources of uncertainties. J Bridge Eng, 2014; 19(4): 04013015.

[33] People' s Republic of China Ministry of Transport (CMT-PRC). Guidelines for seismic design of highway bridges, JTG/TB02-01-2008. Beijing: China Communications Press; 2008 [in Chinese].

[34] Wei $\mathrm{K}, \mathrm{He} \mathrm{HF}$, et al. An endurance time method-based fragility analysis framework for 
cable-stayed bridge systems under scour and earthquake. Ocean Engineering, 2021; 232:109128.

[35] Zhong J, Jeon JS, Yuan WC, DesRoches R. Impact of spatial variability parameters on seismic fragilities of a cable-stayed bridge subjected to differential support motions. Journal of Bridge Engineering, 2017; 22(6):04017013.

[36] Scott B D, Park R, Priestley M. Stress-Strain Behavior of Concrete Confined by Overlapping Hoops at Low and High Strain Rates. Aci Journal, 1982; 79(1):13-27.

[37] $\mathrm{Wu} \mathrm{G}$, et al. Sliding life prediction of sliding bearings using dynamic monitoring data of bridges. Structural Control and Health Monitoring, 2020; 27(5).

[38] Cornell C A. Calculating building seismic performance reliability: a basis for multi-level design norms. WCEE, 1996.

[39] Lee T H. Probabilistic seismic evaluation of reinforced concrete structural components and systems. University of California, Berkeley. 2005.

[40] Azevedo J, Guerreiro L, Bento R, et al. Seismic vulnerability of lifelines in the greater Lisbon area. Bulletin of Earthquake Engineering, 2010; 8(1):157.

[41] Priestley M, Kowalsky M J. Direct Displacement-Based Seismic Design of Concrete Buildings. Bulletin of the New Zealand National Society for Earthquake Engineering, 2000; 33(4). [42] Powell, Graham H. Displacement-Based Seismic Design of Structures. Earthquake Spectra, 2008; 24(2):555-557.

[43] Mervyn J, Kowalsky. A displacement-based approach for the seismic design of continuous concrete bridges. Earthquake Engineering \& Structural Dynamics, 2002; 31(3):719-747.

[44] Su J, Dhakal RP, Wang J. Fiber-based damage analysis of reinforced concrete bridge piers. Soil Dyn Earthq Eng, 2017; 96:13-34.

[45] Jamie E Padgett, Reginald Desroches. Methodology for the development of analytical fragility curves for retrofitted bridges. Earthquake Engineering \& Structural Dynamics, 2010; 37(8):1157-1174.

[46] Hu ZL, Wei B, Jiang LZ, et al. Assessment of optimal ground motion intensity measure for high-speed railway girder bridge (HRGB) based on spectral acceleration. Eng Struct, 2022; 252:113728.

[47] Wei B, Hu ZL, He XH, et al. Evaluation of optimal ground motion intensity measures and seismic fragility analysis of a multi-pylon cable-stayed bridge with super-high piers in Mountainous Areas. Soil Dyn Earthq Eng, 2020; 129(Feb.):105945.1-105945.12.

[48] Zhong J, Pang YT, Jeon JS, Desroches R, Yuan WC. Seismic fragility assessment of long-span cable-stayed bridges in China. Adv Struct Eng, 2016; 19:1797-812.

[49] Zhong J, Jeon JS, Shao YH, Chen L. Optimal Intensity Measures in Probabilistic Seismic Demand Models of Cable-Stayed Bridges Subjected to Pulse-Like Ground Motions. Journal of 
Bridge Engineering, 2019; 24(2).

[50] Zhong J, Jong-Su Jeon, Ren WX, Risk assessment for a long-span cable-stayed bridge subjected to multiple support excitations, Eng Struct, 2018; 176:220-230

[51] Hu ZL, Wei B, He XH, Jiang LZ, Li SS. Effects of Spatial Variation of Ground Motion (SVGM) on Seismic Vulnerability of Ultra-high tower and Multi-tower Cable-stayed Bridges. Journal of Earthquake Engineering, 2021.

Investigation on Multi-Direction Damping System of its seismic control evaluation for a super-long cable-stayed bridge with twin-pylon 